\title{
5
}

\section{MODULATION OF THE IMMUNE RESPONSE IN CRITICAL ILLNESS/INJURY}

\author{
Lesley Doughty, MD \\ Department of Pediatrics, Critical Care Division, \\ Brown University School of Medicine \\ Rhode Island Hospital, Providence, RI
}

\section{INTRODUCTION}

The systemic inflammatory response is elicited in a multitude of clinical scenarios including infection, tissue injury (surgical or traumatic), ischemiareperfusion, post-cardiopulmonary bypass, as well as autoimmune phenomena. There are many factors capable of modulating the magnitude and quality of the immune response during critical illness/injury. Some factors precede critical illness/injury such as chronic poor nutrition, chronic stress (physiologic and/or psychologic), and underlying infectious disease (chronic and acute). Other factors become important modulators during a critical illness/injury including acute stress, infection, tissue injury, poor nutrition, and pharmacologic agents not usually associated with immunomodulation.

What determines the outcome of SIRS episodes remains quite elusive. The pro-inflammatory cytokines produced in early SIRS include TNF $\alpha$, IFN $\gamma$, IL-1 $\beta$, and IL-12. The anti-inflammatory cytokines also induced early include IL-10, IL-4, IL-1 receptor antagonist (IL-1Ra) and soluble TNF $\alpha$ receptor (sTNFR), IL-6, and TGF- $\beta$. Cellular sources of these cytokines include NK cells, monocyte/macrophages, neutrophils, and T cells. A dynamic and evolving balance between these components of the immune system exists. Under physiologic conditions, these mediators provide a communication network throughout the body for activation, amplification, and recruitment of immune cells in order to eradicate pathogens, debride and repair injured tissue, and stimulate $\mathrm{T}$ and $\mathrm{B}$ cells to differentiate into memory cell types for future defense. The function of anti-inflammatory cytokines is postulated to be down-regulation of the pro-inflammatory response and to promote wound healing and memory responses. The recent 
failures of anti-inflammatory strategies in sepsis and multiple organ failure have raised a myriad of hypotheses for this observation. Some focus on timing, suggesting that administration of anti-endotoxin, anti-TNF antibodies, IL-1 receptor antagonists, and anti-platelet activating factor was unsuccessful due to an inability to treat early enough after initiation of the disease process. Other strategies have been aimed at mediators deemed "end effector molecules" such as nitric oxide and these too, have yet to be successful in reducing morbidity or mortality in critical illness/injury. These failures coupled with emerging data describing serious immune perturbations associated with critical illness suggest that there are many critical determinants of successful activation and down-regulation of the inflammatory response in the setting of critical illness/injury.

The previous chapters in this issue have described the essential processes involved in host antimicrobial actions, activation of the innate immune response and its down-regulation as well as the mechanisms of pharmacologic immune suppression. In this section modulation of immune responsiveness, as is seen in clinically relevant scenarios such as systemic stress, brain injury, tissue injury from trauma and surgery, sepsis-induced multiple organ failure, malnutrition, and inadvertent pharmacologic immune suppression will be discussed. In addition, the impact of coincident infection with viruses or parasites at the time of initiation of SIRS will be discussed.

Many of these clinical scenarios have been studied in humans as well as in animal models. Importantly, in humans, strategies used to assess immune responsiveness are limited to a few assays and often do not assess the entire immune system as in animal models. Importantly, only rarely can we assess the function of other than circulating leukocytes, which may not reflect the function of terminally differentiated resident macrophages/dendritic cells or neutrophils, which have already transmigrated out of the vascular space. Given that limitation, describing some of these assays will be helpful in reading through the following data. Human studies mentioned below are of two types, in vivo and ex vivo. Very few studies are actually fully in vivo due to ethical concerns. Some important fully in vivo assessments of immune function include delayed-type hypersensitivity testing by skin anergy panel and the induction of antibody responses to infection/immunization. Many studies consist of sampling serum and or leukocytes from target individuals and conducting measurements of serum mediators and leukocyte content/expression of mRNA or proteins altered during disease states. Recently ex vivo manipulation of leukocytes from 
target individuals has become a convenient technique to assess immune responsiveness. For instance, a trauma victim may have circulating leukocytes sampled, isolated, and then stimulated in cell culture with endotoxin or mitogen. The type and quantity of secreted cytokines can be used as an index of monocyte responsiveness. Some centers are working to derive norms for the release of TNF $\alpha$ by leukocytes in samples of whole blood by carefully controlling LPS type and dose, incubation conditions, and unifying TNF $\alpha$ assay technique. With the definition of norms, this assay may evolve into a clinically useful tool and will be discussed in depth by Volk et al in the following chapter $(1,2)$. In this chapter we will frequently refer to ex vivo LPS-induction of cytokines to describe this type of data. In addition, quantification of circulating monocyte surface expression of HLA-DR, the major histocompatibilty class (MHC) II antigen, which serves as an index of antigen presentation capability and activation state, is frequently used as an index of immune function. Low HLA-DR expression and a poor TNF $\alpha$ response to ex vivo LPS by whole blood is thought to represent a state of "immunoparalysis" in which patients are very vulnerable to infection, may have altered wound healing, and are at risk for refractory multiple organ failure $(1,2)$.

\section{IMPACT OF STRESS ON THE IMMUNE RESPONSE}

A central theme of critical illness/injury is triggering of the stress response consisting of activation of the CNS with consequent stimulation of the hypothalamic-pituitary-adrenal (HPA) axis and the systemic sympathetic/adrenomedullary nervous system. The central integrator of this response is corticotropin-releasing hormone $(\mathrm{CRH})$, which induces $\mathrm{ACTH}$ resulting in cortisol production from the adrenal cortex. CRH also activates the sympathetic nervous system resulting in the release of catecholamines from the adrenal medulla. The results of stress response activation include changes in cardiovascular function to maintain vital organ perfusion, a shift in intermediary metabolism to increase glucose and alternate fuel substrate availability, a shift toward hypercoagulability to optimize hemostasis, and dampening of the inflammatory response. (3-7)

There are several mechanisms by which the stress response impacts on the inflammatory response, many of which are depicted in Figure 1. CRH and ACTH both have direct as well as indirect actions on immune function. $\mathrm{CRH}$ via $\mathrm{ACTH}$ induces cortisol production by the adrenal cortex. Cortisol 
preferentially decreases expression of IL-12, a key pro-inflammatory cytokine produced by antigen presenting cells (APCs) such as

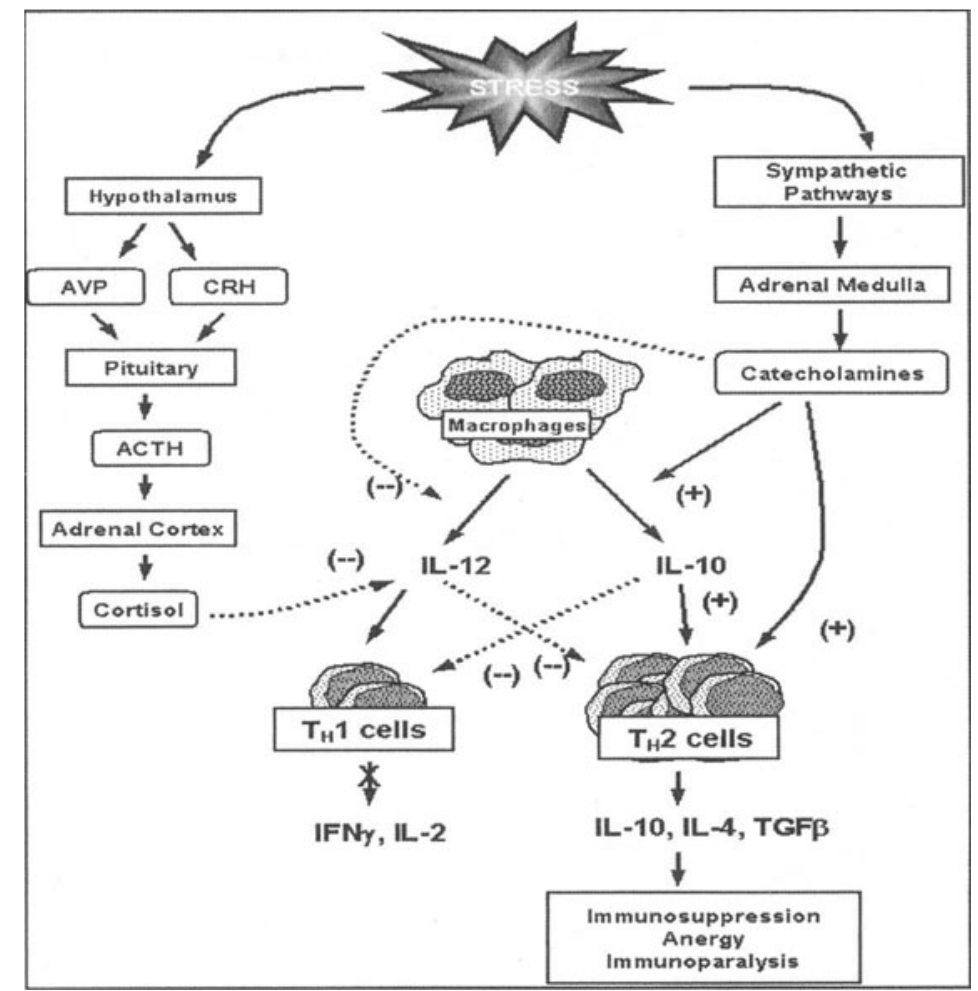

Figure 1: The pathway from stress to immunosuppression.

monocyte/macrophage/dendritic cells, which is critical for the $T_{H} 1 \mathrm{~T}$ cell cytokine expression (TNF $\alpha$, IFN $\gamma$, IL-6, IL-1 $\beta$, IL-2, and IL-8). By diminishing both IL-12 production by APCs and IL-12 receptor expression on $\mathrm{T}$ and NK cells, cortisol results in diminished IFN $\gamma$ production and a shift of the $\mathrm{T}$ cell phenotype to an anti-inflammatory state favoring the production of $\mathrm{T}_{\mathrm{H}} 2$ cytokines (IL-10, IL-4, IL-5, IL-13, TGF $\beta$, and IL$1 \mathrm{Ra})(8)$. Cortisol also decreases the expression and cellular actions of other inflammatory mediators such as adhesion molecules, nitric oxide, prostanoids, platelet activating factor, and reactive oxygen intermediates such as superoxide. The mechanisms employed by cortisol are varied and include altering transcription rates, stability of transcripts, and blocking of third messengers such as transcription factors NFkB and AP-1, and cAMPresponsive element binding protein (CREB) $(5,7,8)$. 
In addition to stimulation of cortisol via $\mathrm{ACTH}, \mathrm{CRH}$ also activates the sympathetic nervous system, which spans from the brain stem nuclei via preganglionic efferent fibers to the paravertebral chains and the prevertebral ganglia. Postganglionic efferents extend to distal innervated tissues such as the adrenal medulla inducing the secretion of epinephrine mostly and norepinephrine to a much lesser degree $(5,7,9)$. Most postganglionic fibers are noradrenergic innervating many other tissues such as the smooth muscle of the vasculature participating in vasomotor tone as well as areas of lymphoid tissue rich in T cell, macrophages, mast cells, and plasma cells.

Some authors interpret a consistent association of noradrenergic fibers with thymic $\mathrm{T}$ cells and mast cells to indicate a role for norepinephrine and histamine in $\mathrm{T}$ cell development (7).

Neuropeptidergic postganglionic fibers also innervate lymphoid and nonlymphoid tissues and are particularly concentrated in zones rich in $\mathrm{T}$ cells, macrophages, and mast cells. The consequence of this neural input can either be pro- or anti-inflammatory. Peripheral release of CRH and Substance $\mathrm{P}$ can trigger mast cell degranulation with resultant histamineinduced effects including enhancing vascular permeability and vasodilation, $T$ cell proliferation, and IL-2 receptor expression $(5,7,9,11)$. Substance $P$ can also induce respiratory burst and release of the pro-inflammatory cytokines such as IL-1, IL-6, TNF $\alpha$, and IL-12 from macrophages (13). Anti-inflammatory actions occur via pro-opiomelanocortin (POMC)-derived peptides such as $\beta$ endorphin, somatostatin, and $\alpha-\mathrm{MSH}$ (12-15). Afferent nerve fibers also participate in the neuro-immune circuit. Inflammatory mediators and pain in peripheral tissues can induce the release of neuropeptides such as Substance $P$ and calcitonin gene-related peptide (GCRP) leading to alterations of vascular permeability and chemotaxis of leukocytes to these sites (14-17).

Catecholamines released as a result of adrenal medullary stimulation exert very potent immunosuppressive effects on leukocytes bearing the $\beta$ receptor, which include NK cells, lymphocytes, and monocyte/macrophages. NK cells are exquisitely sensitive to sympathetic activity. Within one hour of central administration of $\mathrm{CRH}$ NK cell lytic and cytotoxic activity is significantly depressed (7). Treatment with $\beta$ agonist and inhibition by $\beta$ receptor blockade has revealed that modulation of NK cell function can occur through sympathetic nervous system stimulation $(18,19)$.

Macrophage/monocyte and T cell functions are also altered by $\beta$-adrenergic receptor activation by either circulating endogenous catecholamines and by 
exogenously administered catecholamines. Ex vivo LPS-induced TNF $\alpha$ production by circulating leukocytes is suppressed by $\beta$ agonists $(20$, 21). This suppression is reversible with $\beta$ blocking agents such as propranolol and to a lesser degree by $\alpha$-adrenergic blocking agents. $\beta$ receptor activation results in activation of adenylate cyclase which increases the cAMP levels leading to suppression of TNF $\alpha$, IL-12, and IFN $\gamma$ production and augmentation of IL-10 production (20-23). This shift in balance favoring anti-inflammatory cytokine over pro-inflammatory cytokine response may be due to differential expression of $\beta$ receptors on Th1 $>$ Th2 cells allowing for $\beta$ agonist mediated suppression of Th1 cytokine production $(8,24-26) \beta$ adrenergic stimulation through cAMP can block signaling through the transcription factor $\mathrm{NF \kappa B}$ which is a critical proinflammatory signaling pathway. One report has demonstrated $\beta$ adrenergic-mediated suppression of IKB degradation preventing $\mathrm{NF \kappa B}$ nuclear migration and DNA binding (27).

To date, the impact of $\alpha$ adrenergic stimulation on immune function remains controversial. Differences in leukocyte maturation and local environmental differences may explain conflicting data concerning the pro or antiinflammatory role of $\alpha$ adrenergic stimulation. Abraham et al have demonstrated inhibitory effects of $\alpha_{2}$-adrenergic stimulation on neutrophil accumulation in the lung and activation state due to endotoxin administration (28). Conversely, Spengler et al have demonstrated augmented macrophage-derived TNF $\alpha$ after $\alpha$-adrenergic stimulation (29). Some micro-environmental factors thought to impact on the ultimate response to adrenergic stimulation include mediators such as substance $P$, peripheral $\mathrm{CRH}$, histamine, and the state of activation or differentiation of macrophages when stimulation occurs. Laffon et al demonstrated that $\alpha$ adrenergic stimulation inhibits fluid clearance across the alveolar epithelium in a hemorrhagic shock model (30). These data indicate that $\alpha$ adrenergic stimulation in the lung may play a role in the development of ARDS after significant systemic stressors possibly due to the release of neuropeptides impairing fluid clearance from inflamed sites.

\section{THE IMPACT OF INFLAMMATION ON THE STRESS RESPONSE}

The above discussion focused on the immune modulating effects of the stress response. This section will highlight data demonstrating that elements 
of the immune response can trigger activation of both the hypothalamicpituitary-adrenal axis and the sympathetic nervous system resulting in a counter-regulatory dampening of the pro-inflammatory response. Teleologically, this regulatory response may protect an organism from overshooting with an exaggerated or protracted pro-inflammatory response with consequent tissue-injury. There is a great deal of data demonstrating this by mechanisms ranging from initiation of inflammation in the periphery to instillation of inflammatory cytokines directly into the CNS. The cytokines thought to be capable of communicating with the CNS are TNF $\alpha$, IL-1 $\beta$, and particularly IL-6 individually and importantly, in combination, their effects are synergistic (31-33). These cytokines can directly induce $\mathrm{CRH}$ from hypothalamic tissue ex vivo however, neutralization of IL-6 nearly ablates this effect indicating that IL- 6 is an important mediator in this pathway $(6,31)$. Further, IL-6 is an extremely potent direct inducer of both ACTH and arginine vasopressin (AVP) from the hypothalamus. This effect is inhibited by prostaglandin inhibitors, suggesting a role for prostaglandins in this communication (33). The site of action and route into the CNS of circulating cytokines remain poorly understood. It is not known whether cytokines act on areas of the brain outside the blood brain barrier such as the median eminence or the area postrema or whether a vascular cytokine-to endothelial-cytokine/prostanoid-to glial cell cascade exists (5-7).

Leukemia inhibitory factor (LIF) is another pleiotropic inflammatory cytokine with very potent CNS effects. Expression is upregulated by proinflammatory cytokines in many inflammatory states peripherally and plays an important role in leukocyte trafficking (34). In animal models, hypothalamic and pituitary LIF expression is induced by LPS (35). LIF deficient mice exhibit a very poor ACTH response to restraint stress and corticosterone response to LPS demonstrating that LIF is required for the HPA stress response $(34,36)$. LIF stimulates POMC gene expression as well inducing the glucocorticoid arm of the stress response both with antiinflammatory effects $(35,36)$. In this way, LIF may prove to be very important at the immune:neuroendocrine interface.

A neural route of cytokine to brain communication is postulated to be mediated by local increases in inflammatory cytokines capable of stimulating the HPA axis and the sympathetic system through nociceptive, visceral, and somatosensory afferents. Several authors have demonstrated that subdiaphragmatic vagotomy attenuates intraperitoneal LPS-induced IL$1 \beta$ expression in brain tissue, fever, $\mathrm{CRH}, \mathrm{ACTH}$, corticosterone, and the response to peripheral immune challenge (38-42). Further supporting this 


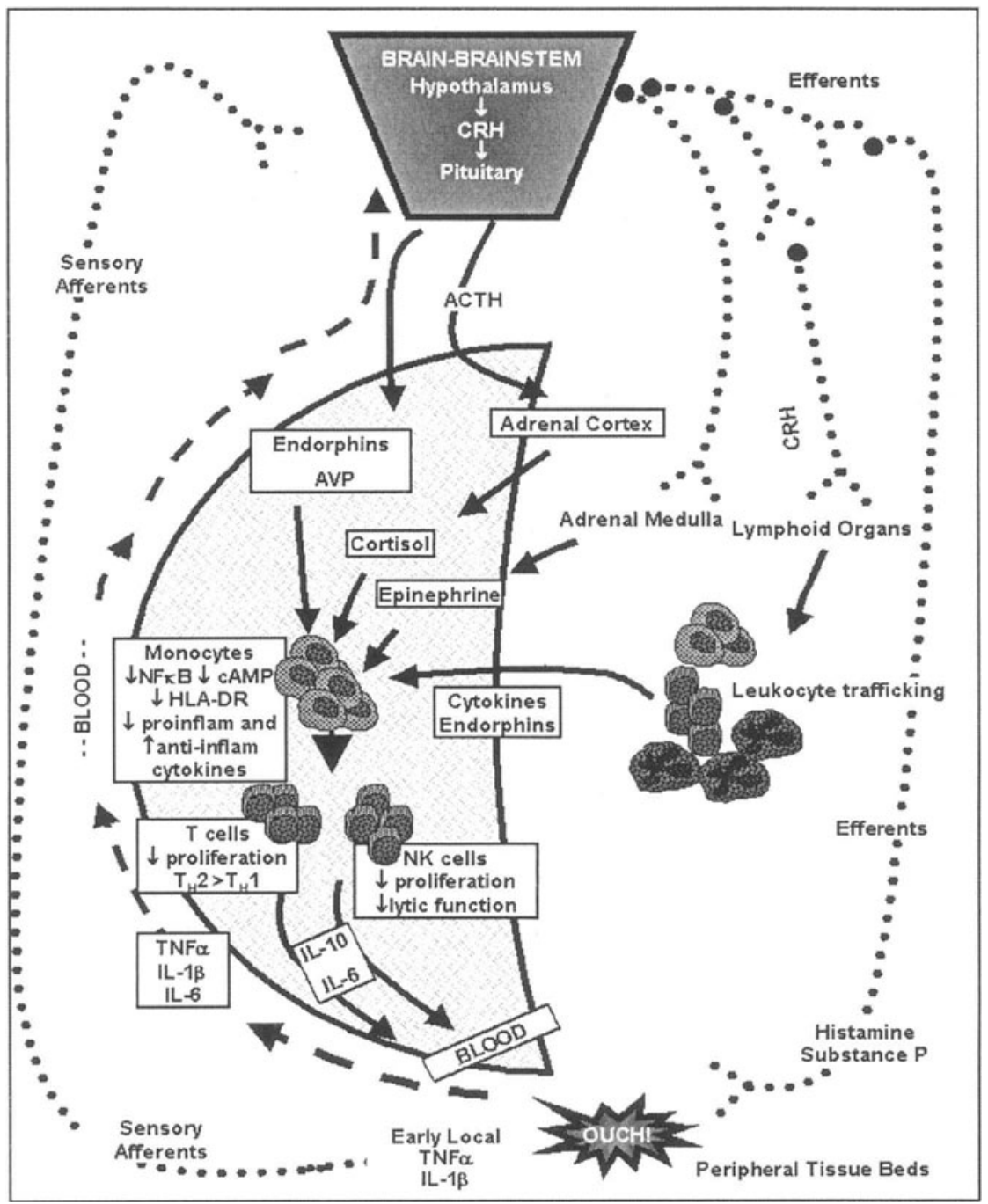

Figure 2: The Neuro-endocrine-immune axis. Pain/inflammation begins in the peripheral tissue bed with the local release of cytokines, which activate sensory afferents and thereby communicate with the brain. The central stress activator CRH is released leading to secretion of ACTH, endorphins, and AVP. ACTH reaches the adrenal cortex via the bloodstream inducing cortisol release. Via sympathetic innervation the adrenal medulla releases catecholamines such as epinephrine. Sympathetics innervating peripheral tissue beds and lymphoid organs cause the release of histamine and substance $P$ as well as activating and mobilizing leukocytes. Cortisol, endorphins, and epinephrine all act to downregulate the inflammatory response by altering monocyte, lymphocyte, $\mathrm{NK}$, and $\mathrm{T}$ cell function to favor the anti-inflammatory response and the immunoparalyzed state. 
concept are data demonstrating increased expression of c-fos, a neuronal activation marker, in primary vagal afferents after intraperitoneal LPS administration (43). In addition, within 60 minutes of intraperitoneal LPS administration increased IL- $1 \beta$ in perivagal macrophage/dendritic cells and IL-1binding sites in vagal paraganglia occur prior to the appearance of IL$1 \beta$ in the serum (38). These data suggest that perivagal immune cells may rapidly respond to intraperitoneal LPS and due to their proximity to vagal afferents, IL-1 $\beta$ may not need to be free in the peritoneal fluid or serum to signal the brain (38). These data present compelling evidence for the concept of neural signaling to the CNS from local inflammatory sites via sensory afferents as depicted in Figure 2.

The importance of the counter-regulatory stress response in dampening or controlling the magnitude of the systemic inflammatory response can be demonstrated by the response to endotoxin in adrenalectomized or hypophysectomized animals. Several authors have demonstrated that LPS, TNF $\alpha$, and IL- $1 \beta$-induced lethality is much higher when the HPA axis and/or the sympathetic response is ablated (5-7). Thus the immune and neuroendocrine systems maintain a delicate balance to both mount an appropriate response for the eradication of pathogens and to prevent lethal immune-mediated tissue injury in the process. Unfortunately, this balance is not always maintained optimally due to acute and overwhelming or chronic severe stressors, sequential insults resulting in altered responsiveness, or medications/therapies, which inadvertently shift this balance.

In this next section, immune alterations following traumatic injury, hemorrhage, surgery, septic shock, other concurrent infections, and by the pharmacology commonly used in critical care settings will be discussed. It is important to note that underlying all of these scenarios is or has been recent activation of the stress response either primarily or by the elaboration of cytokines resulting in secondary activation.

\section{THE IMPACT OF TRAUMATIC OR SURGICAL INJURY ON IMMUNE FUNCTION}

Numerous reports have demonstrated activation of the systemic inflammatory response by traumatic injury and/or hemorrhagic shock. Production of many pro and anti-inflammatory mediators as well as activation of monocytes, neutrophils, and lymphocytes has been reported 
after trauma much like that seen in sepsis (43-50). The immune response triggered by trauma and/or hemorrhage is thought to be due to soft tissue injury, bony injury, shock with possible bacterial translocation from the gut, and ischemia/reperfusion injury (43-50). Cytokine activation correlates with clinical indices of trauma severity, which predict the development of posttrauma complications such as infection and multiple organ failure $(43,45$, $51,52)$. Although the immunologic response to trauma begins within minutes of the traumatic event, there is an overwhelming body of data demonstrating profound depression of immune function very early posttrauma persisting for several days $(43-50,53-60)$.

Aspects of the immune response altered after trauma include both innate and adaptive functions. Monocyte/macrophages exhibit decreased pro- and increased anti-inflammatory cytokine production in response to ex vivo LPS, decreased HLA-DR expression and decreased antigen presentation capability $(43-46,50,53,58,59)$. In addition, release of prostaglandins, thromboxanes, and procoagulant factors such as tissue factor and plasminogen activator inhibitor are increased shortly after traumatic insult (60). Neutrophils exhibit decreased bactericidal activity, respiratory burst, chemotaxis, $\beta$-integrin expression, degranulation, and phagocytic capacity associated with decrease serum opsonization $(44,61)$. Lymphocytes produce increase $T_{H} 2$ cytokines and decreased $T_{H} 1$ cytokines, decreased delayed-type hypersensitivity response, decreased mitogen-induced proliferation, IL-2 production, and IL-2 receptor expression, and decreased immunoglobulin production $(47-49,57)$. Decreased NK cell activity also has been reported after trauma (43). Multiple authors have demonstrated induction of anergy and poor antibody response to antigen stimulation after trauma/surgery also indicating in vivo this important immune defect (5456). In effect, all aspects of the immune response are suppressed after the initial inflammatory response to trauma.

The nature of the trauma matters little, similar effects are seen after soft tissue, bony, hemorrhagic, ischemia/reperfusion, and burn injuries. Wichmann et al showed that there is additive effect on immune depression when several types of injury coexist (60). Ayala et al examined immune depression induced by cecal ligation and puncture (CLP) with polymicrobial sepsis, cecal ligation alone, cecal ligation plus endotoxin infusion, and endotoxin infusion alone (62). They report that cecal ligation alone could change macrophage responsiveness to endotoxin to a low IL-12 and high IL10 response. In terms of survival, however, neither cecal ligation nor endotoxin proved to be lethal in their model. The combination of the two 
was synergistic but still far less lethal than CLP (33 vs. $80 \%$ respectively) (62). This work importantly highlights the impact of tissue injury on cellular responsiveness creating a $\mathrm{T}_{\mathrm{H}} 2$ anti-inflammatory environment, which may explain the large difference in lethality in the CLP group with polymicrobial sepsis compared to sterile but inflamed conditions such as in cecal ligation plus endotoxin.

The consequence of immune depression clinically is a greater risk for infection and for mortality post-trauma. In fact, many studies have demonstrated increased morbidity when immune responsiveness is depressed. Christou et al, and Puyana et al described higher rates of morbidity and mortality in trauma patients who were anergic $(54,56)$. Some of these patients demonstrated global anergy- depression in both the $\mathrm{T}_{\mathrm{H}} 1$ and $\mathrm{T}_{\mathrm{H}} 2$ cytokines responses rather than a predominance of antiinflammatory $\mathrm{T}_{\mathrm{H}} 2$ cytokines $(55,56)$. Neidhardt et al reported increased serum IL-10 levels in trauma victims compared to healthy controls. In addition, IL-10 levels were highest in those who developed post-traumatic sepsis or multiple organ failure syndrome (MOSF), nonsurvivors, and those with clinical trauma scores indicating severe injuries (45).

Regulation of the inflammatory response after trauma is complex and multifaceted. Triggering a pro-inflammatory response results in activation of NFKB by TNF $\alpha$ and cAMP by prostaglandins as well as initiating a stress response with the release of cortisol and catecholamines all of which lead to production of numerous powerful anti-inflammatory mediators such as IL10, IL-1ra, sTNFR, TGF $\beta$, and IL-4. This response is capable of downregulating the pro-inflammatory response, changing the immune milieu to a state of immune depression or "immunoparalysis" $(1,43-46,58$, $59,60,61)$. These authors specifically refer to decreased HLA-DR expression with decreased antigen presentation capacity and reduced exvivo LPS-induced production of $\mathrm{TNF} \alpha$, IL-10, and reactive oxygen intermediates $(1,43-46,58,59,60,61)$. Bone has described this state as the "compensatory anti-inflammatory response syndrome" (CARS) and like immunoparalysis and anergy, is reported after trauma, burns, and hemorrhage and is associated with increase risk for septic complications and mortality $(63,64)$. In addition, real-time monocyte HLA-DR expression and TNF $\alpha$ induced by ex vivo LPS stimulation of leukocytes in whole blood provide the basis for ongoing immuno-monitoring trials for the critically ill which will be discussed in a later chapter of this text $(1,2,65,66)$. 
Surgical patients are examples of controlled, optimized trauma with the benefit of anesthesia and optimization of oxygenation and perfusion during the "traumatic event" imposed by the surgical procedure. The magnitude and type of surgery as well as the type of anesthetic used can impact on the activation of the intra- and peri-operative stress response and the immune response elicited which may affect infectious complications, wound healing, and thrombotic events during the postoperative recovery phase $(61,67,68)$.

To demonstrate the impact of the magnitude of surgical procedures on neurohormonal and immune axes, several studies have demonstrated that laparoscopic procedures induce less stress hormone production, immune depression, and endogenous endorphins compared to open laparotomy procedures. For instance, cellular immunity indices such as the DTH response, mitogen-induced proliferative response, monocyte HLA-DR expression, plasma ACTH, cortisol, catecholamines, and $\beta$ endorphins were more deranged post laparoscopic vs. open cholecystectomy (69-72).

Circulating levels of inflammatory cytokines (pro and anti) are elevated and correlate with the morbidity of surgeries when endotoxin is elaborated or when significant ischemia and reperfusion is involved such as during aortic aneurysm repair. Welborn et al and Holzheimer et al describe increased plasma levels of endotoxin and pro and anti-inflammatory cytokines, which correlated well with indices of organ dysfunction and aortic cross clamp time $(73,74)$. Oldenburg et al demonstrated higher levels and longer duration of circulating IL-10 in thoracic vs abdominal aortic aneurysm repair. They too found that IL-10 correlated with organ failure and ischemic time (75). Ziegenfuss et al reported diminished ex vivo LPS induced TNF $\alpha$ beginning after declamping of the aorta (76). Neutrophil activation with upregulation of $\mathrm{CD} 1 \mathrm{~b}$ also correlates with visceral ischemic time (77). These data provide compelling evidence for ischemic activation of the inflammatory response with activation of the counter-regulatory antiinflammatory response as well. Post-operatively, depressed immune function will render patients extremely vulnerable to organ dysfunction and infection. This has been well described by Wakefield et al who found that monocyte HLA-DR expression after major elective surgery was markedly reduced from preoperative values beginning day 1 (50). This effect was most pronounced in patients who developed postoperative septic complications. Hensler et al, however, found a defect in antigen presenting cell-independent $\mathrm{T}$ cell proliferation after surgery suggesting yet another aspect of immune dysfunction consequent to activation of the stress and inflammatory response (57). 
Such immune phenomena have also been observed in post cardiopulmonary bypass (CPB) cardiac surgery patients. Contact with the $\mathrm{CPB}$ circuit activates leukocytes to produce pro-inflammatory cytokines within 90 minutes. No anti-inflammatory cytokine induction was seen, however, the limited time frame analyzed may have precluded a full inflammatory response analysis (78). Changes in $\mathrm{T}$ cell subsets demonstrating considerable reductions in $\alpha \beta$ as well as $\gamma \delta$ subsets of T cells persisting 3-7 days after CPB have been reported in children (79). In addition, Markewitz et al reported suppression of $T_{H} 1$ function with preservation of $T_{H} 2$ function post-CPB (48). Flohe et al extended these observations by demonstrating both a reduction of HLA-DR expression and ex vivo LPS-induced TNF $\alpha$ response post-CPB. The severity and refractoriness of this immune depression was not as great as that seen in severe trauma or sepsis (80). Therefore, the persistence and degree of immune modulation post-insult correlates with insult magnitude and the degree to which the immune system is stimulated initially.

\section{IMPACT OF ANESTHETIC/ANALGESIA ON IMMUNE FUNCTION}

Many reports discuss the impact of anesthetic agents on the stress response and consequently, the immune response as well as direct manipulation of the immune response by other mechanisms. One approach has been to block sensory afferents in an attempt to decrease the stress response induced by the surgery. Epstein et al report that this approach stemmed from early animal studies and clinical studies demonstrating attenuation of the stress response during injury/surgery to denervated parts of the body either through experimental denervation or in paraplegic individuals (61). The use of regional anesthetics has been variably successful in blocking the stress response with more success in minor procedures compared to more invasive procedures. Ramanathan et al reported that epidural anesthesia up to the T-4 dermatome for cesarean section during preeclampsia resulted in less release of ACTH, $\beta$-endorphins, and catecholamines compared with general anesthesia for the same procedure/conditions (81). Tsuji et al also demonstrated significant reduction of stress hormones with epidural vs. general anesthesia for gastrectomy. Interestingly, in this study vagotomy or vagal block added no further benefit above that seen with epidural anesthesia (82). Rosenfeld et al and Perler et al reported fewer vascular graft 
occlusions and lower plasminogen activator inhibitor levels in patients receiving regional anesthesia for vascular surgery $(83,84)$. Norman et al, however, failed to demonstrate a difference in terms of stress hormone, catecholamine, or cytokine induction post-operatively following an abdominal aortic repair by using epidural vs general anesthesia (85). Although Naito et al demonstrated suppression of the stress response and a lack of cytokine production using epidural anesthesia for unilateral hip replacement surgeries they demonstrated increased ACTH, cortisol, endotoxin, and cytokine levels after pancreatoduodenectomy. They speculated that the release of endotoxin from surgical manipulation of bowel was capable of inducing stress response and cytokine production despite epidural anesthesia (86). This study is important because it demonstrates that blockade of the stress response requires both neural blockade as well as humoral blockade. In addition, there are several other reports showing no benefit especially when associated with major surgery such as CABG and aortic aneurysm repair, both surgeries involving ischemia and reperfusion of organs, which like Naito's latter example represent much more severe systemic perturbation (61). Overall, there is increasing evidence to support the reduction in complications associated with regional anesthesia compared with general anesthesia except for those procedures inducing severe systemic perturbations. The data cited above suggest that some of these benefits may be from a reduced stress response resulting in less perturbation of the immune system protecting patients from infectious, thrombotic, or wound healing difficulties postoperatively.

The choice of intravenous and/or inhaled anesthetic has also been investigated for better stress and immune function protection. The production of endogenous opioids is increased by stress. The arcuate nucleus in the CNS and peripheral blood mononuclear cells (PBMC) in the periphery are sources of $\beta$-endorphins which exert local immunosuppressive effects in the brain and via stimulation of the $\mu$ opioid receptors present on PBMCs $(15,87)$. $\beta$-endorphin administration results in decreased mitogeninduced proliferation whereas the use of endorphin antagonists increases NK cell activity, increases lymphocyte proliferation, and a shift from $\mathrm{T}_{\mathrm{H}} 2$ to a $\mathrm{T}_{\mathrm{H}} 1$ cytokine profile. $(15,87)$ Opioid antagonists induce increased levels of monocyte chemoattractants MCP-1, RANTES, and IP-10 demonstrating an important role for endogenous opioids in leukocyte trafficking (88).

By binding the opioid receptors on PBMC morphine, like $\beta$-endorphins, can exert immunosuppressive effects. Welters et al demonstrated that morphine suppressed complement function, Fc gamma receptor expression, and 
neutrophil phagocytic as well as respiratory burst activity. These effects were inhibitable with naloxone and nitric oxide inhibitors indicating a morphine-stimulated nitric oxide mechanism involved with neutrophil dysfunction $(89,90)$. Welters et al also demonstrated that morphine through nitric oxide release inhibited NFKB activation, a key transcription factor involved in gene expression of many important inflammatory cytokines (91). Some data suggests that natural opiates exhibit more immunosuppressive effects compared with the synthetic derivatives, however this remains controversial. $(92,93)$ In summary, the choice of anesthetic agent and analgesics can impact on immune function by several routes. An anesthetic agent, which insufficiently blunts the stress response, may lead to immunosuppression by systemic release of catecholamines, glucocorticoids, as well as via endogenous $\beta$ endorphin release. Alternatively, the choice of natural opiates as part of an anesthetic or for post-operative analgesia may exert immunosuppressive effects through the opioid receptor on leukocytes thereby increasing the risk for post-operative complications.

\section{TRANSFUSION-INDUCED IMMUNOMODULATION}

Allogeneic blood transfusion-induced immunomodulation (TRIM) is a controversial concept focused on immunosuppression seen after blood transfusion. In numerous studies TRIM has been implicated in improving renal allograft survival, increasing post-operative bacterial infection and the development of MOF after trauma, increasing malignancy recurrence rate, reducing Crohn's disease recurrence rate, reactivating chronic viral infection, and delaying wound healing $(94,95)$. In some reports these posttransfusion effects persist for several weeks. Several mechanistic theories exist including transfer of allogeneic cells resulting in impairment of $\mathrm{T}$ and NK cell proliferation, augmentation of anti-inflammatory cytokine release as well as decreased phagocyte function to explain its role in the above mentioned situations $(94,95)$. Soluble factors such as Fas ligand and HLA class 1 molecules have also been implicated including cytokines and cytokine receptors released by leukocytes transferable via PRBC supernatant $(96,97)$. These effects are related to leukocyte content with less immunosuppression seen from PRBC units that are leukocyte filtered prior to storage in the blood bank $(98,94)$. Although this concept has been extensively studied in observational and animal studies, the results of randomized controlled studies remain contradictory. The use of leukocyte- 
reduced blood has become standard procedure in many countries including the United Kingdom, Canada, and France however, in the USA it has not been universally adopted and remains controversial $(94,95)$. Current estimates however indicate that due to practices of many of the major blood banking organizations such as the American Red Cross, $60-75 \%$ of blood in the USA is leuko-reduced (99).

In addition to leuko-reduction, evidence is also mounting for deleterious effects of storage time even in leuko-reduced PRBCs. Biffl et al and ChinYee et al. demonstrated that supernatant from stored PRBC units activated and primed healthy cultured neutrophils for superoxide production and delayed apoptosis $(100,98)$. This effect occurred after 21 days of storage and worsened until unit expiration. Importantly, this effect occurred despite pre-storage leuko-reduction, however, was abolished by post-storage RBC washing with saline (100). These data indicate that pre-storage leukoreduction may not be sufficient to make transfusion of blood an "immunoneutral" event and that post-storage washing or the use of fresher blood may be important in optimizing immune function.

These data provide compelling evidence for modulation of the immune response after trauma, burns, hemorrhage, and surgery induced by tissue injury and activation of the stress response inherent in any of these settings. In the surgical setting, anesthetic choices may impact directly on immune function as in the case of narcotics or may modulate the impact of the surgical procedure on immune responsiveness as seen with epidural anesthesia. In the post-trauma/surgical critical care setting, patients facing nosocomial infection, wound infection, and wound healing challenges are significantly disadvantaged. These concepts may be key to the lack of success of numerous anti-inflammatory strategies for the treatment of septic shock in the past decade. Also, these data contribute to the body of literature supporting the need for immune monitoring to identify potential benefit from either immune boosting or immune suppressing strategies in the critical care setting, which will be addressed later in this issue.

\section{BRAIN INJURY RELATED IMMUNE MODULATION}

Profound immune suppression has been demonstrated after injury to the brain either traumatically or surgically-induced. Initially studies focused on the observed serious infection-related morbidity and mortality seen in up to $50-75 \%$ of isolated head injury patients (101-105). In a series of articles 
Quattrochi et al assessed numerous features of the cell mediated immune response and found anergy to DTH stimulation in $100 \%$ persisting up to 2 weeks after injury. Sixty-percent of these patients developed infection, mostly within the first week post-injury $(101,106-108)$. Wilson et al showed that $79 \%$ of anergic vs $27 \%$ of nonanergic brain injured children became infected (103). Quattrocchi's group reported changes in PBMC, which included decreased T-helper cells, decreased IL-2 responsiveness of T cells, cytotoxicity, and PHA-induced IL-2, IFN $\gamma$, and proliferation (106-108). Depressed HLA-DR expression on circulating monocytes occurs transiently following neurosurgical procedures. Patients who develop infection postoperatively had lower HLA-DR expression compared with those without infection. In 10 patients with HLA-DR $<30 \%$ (a marker of immunoparalysis), 9 developed infection (105). These authors report the reduction in HLA-DR expression on peripherally circulating monocytes coincided with induction of inflammatory cytokines in the cerebrospinal fluid (CSF) but not in the plasma (105). Several authors have shown cytokine activation in the CSF peaking 1-2 days after head injury or neurosurgery and persisting for up to 2 weeks including both pro and antiinflammatory cytokines, such as IL-12, IFN $\gamma$, IL-6, IL-8, TGF $\beta$, and IL-10, as well as soluble adhesion molecules (109-115). Minimal systemic cytokine elevation can be found after isolated head injury or surgery. By using a CSF-/serum-albumin quotient technique and by studying blood:brain barrier dysfunction it appears that cytokines such as IL-6 found at low levels in the periphery after brain injury may originate from the CNS (109, 111). These data not only imply a CNS source for cytokines but also a connection from within the CNS to affect monocyte function outside of the CNS. For instance, Woiciechoswsky et al reported that low level increases in serum IL- 6 on day 1 after traumatic brain injury were predictive of brain injury severity, mortality, and infectious complications (111). In this way, CNS-derived cytokines in addition to stress mediators such as ACTH and cortisol, released after injury or neurosurgical manipulation, induce an immunosuppressed peripheral state leading to increased morbidity and mortality from brain injury $(116,117)$. These authors have demonstrated that neurosurgical manipulation of the brain results immunoparalysis with a rapid rise of systemic IL-10, decreased monocyte HLA-DR, and poor ex vivo PBMC response to LPS compared to presurgical measurements (117). This was especially true when brain stem compression was present. They relate systemic release of IL-10 to sympathetic activation and show prevention of the rise in IL-10 by pretreatment with $\beta$ blockers in an animal model (117). They present data to support that brain injury-related intracerebral cytokine elaboration (IL-1 $\beta$, TNF $\alpha$. and IL-6) stimulates the 
HPA axis leading to sympathetic activation which leads to elevated systemic IL-10 production, decreased HLA-DR, and decreased inflammatory response to LPS ex vivo (116). This mechanism may not only be the cause of immune depression following brain injury but also supports the general understanding of how stressful circumstances alter immunoresponsiveness.

\section{SEPTIC SHOCK}

During septic shock a similar immunosuppressed state has been demonstrated as seen after trauma, burns, hemorrhage, major surgical procedures, and brain injury. During septic shock many of the same systemic influences are present as in the above situations- elicitation of the stress response, activation of the inflammatory response, use of catecholamines, and often use of narcotics for sedation/pain relief. What differs between these processes is the activation of the inflammatory response to overwhelming infection as a primary event. To date, numerous reports indicate that although the pathophysiology of septic shock is largely immune response-mediated, once the inflammatory response is initiated, the host becomes incapable of responding normally to subsequent inflammatory challenges. This phase of septic shock has been called "immunoparalysis" and the "compensatory anti-inflammatory response syndrome (CARS)" by different authors $(2,63-65,116)$. As in trauma/injury, in septic shock with multiple organ failure, circulating monocytes display the phenotype associated with a deactivated state- low HLA-DR expression, loss of antigen presentation capacity, and decreased TNF $\alpha$ response to in vitro stimulation with LPS (65). In addition, NK cells are hyporesponsive, and lymphocytes are hyporesponsive, anergic, proliferate poorly, and undergo apoptosis $(65,118-123)$. Although many mediators both pro and anti-inflammatory are present 24-48 hours after the initiation of septic shock, the overall phenotype of circulating leukocytes is characterized by a hyporesponsive pro-inflammatory and hyperactive anti-inflammatory response to subsequent stimulation with LPS or mitogens $(65,124)$. We have much more animal data than human to explore the responsiveness of tissue leukocytes but to date these cells are hyporeactive as are those in circulation $(125,126)$.

Clinically, experience with HLA-DR expression and the responsiveness to LPS ex vivo is becoming widely reported as an index of immune responsiveness in different clinical scenarios. Patients in many stressed and life-threatened conditions display alterations in these variables transiently. In those patients who develop multiple organ failure as a consequence of 
life-threatening events such as septic shock, a continued depression of HLADR expression and poor responsiveness to ex vivo LPS portends worse survival and high risk for nosocomial infection (1,2, 63-65). Survivors of MOF in these states display recovery of these indices (127). Experimentally, treatment with IFN $\gamma$ or GM-CSF can reactivate monocyte HLA-DR expression and restore monocyte responsiveness to ex vivo LPS $(1,65)$.

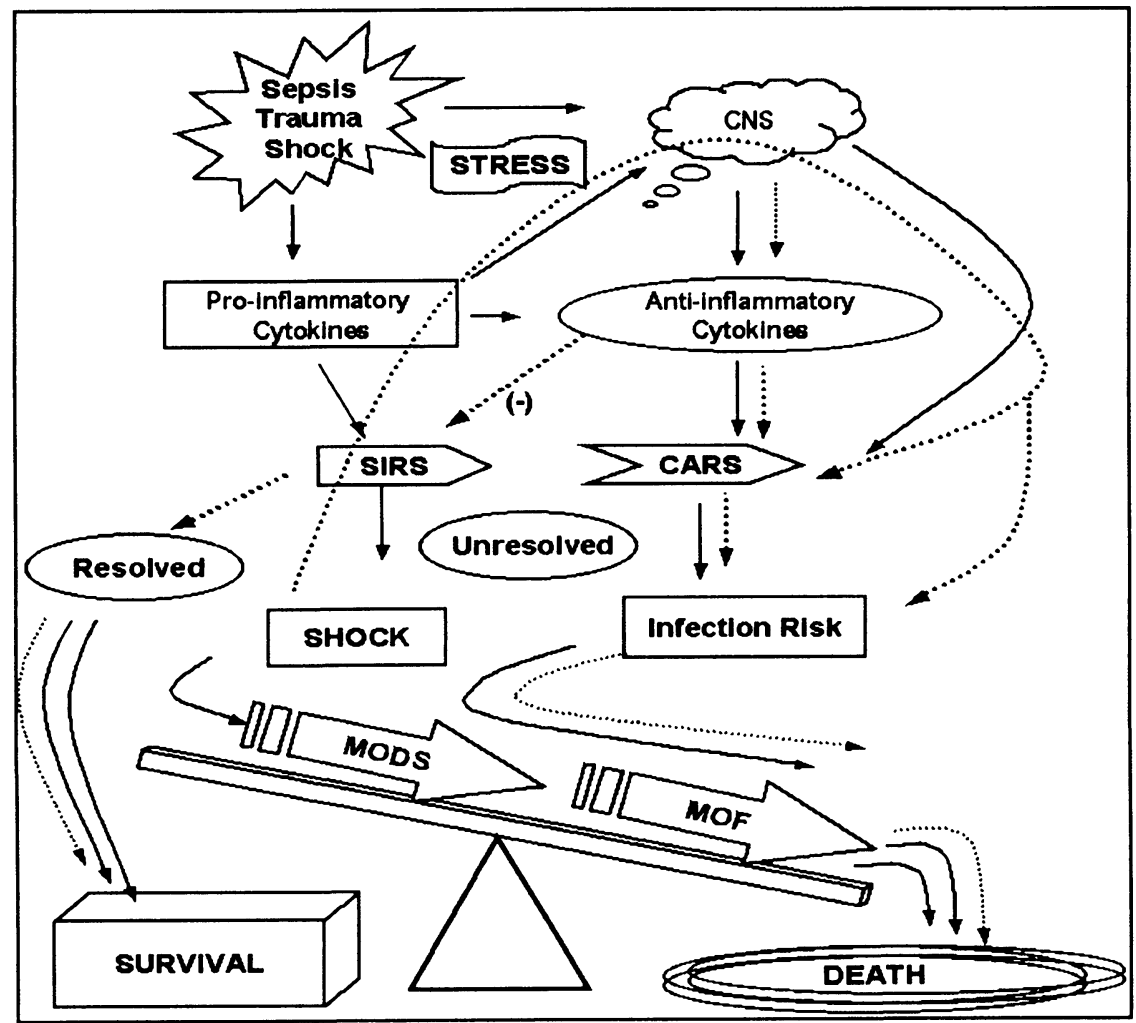

Figure 3: The compensatory anti-inflammatory response. An initial episode of sepsis/trauma/ \pm shock induces pro-inflammatory cytokines as part of SIRS which may lead to shock and if severe can induce MODS, MOF, and death. The compensatory anti-inflammatory response is induced by stress, pro-inflammatory cytokines, and shock from SIRS. It serves to downregulate SIRS leading to appropriate resolution and survival. If unresolved, secondary infection risk is high and in this state if infection occurs, MODS, MOF, and death can be the result.

Treatment of trauma patients and patients with septic shock with either IFN $\gamma$ or GM-CSF has been tried however, the results have not unequivocally been beneficial $(65,128-131)$. Kox et al however, reported improvement in 
patient survival, monocyte HLA-DR expression, and ex vivo LPS response in a small study of 10 patients with sepsis who prior to treatment with immune stimulation displayed depressed HLA-DR expression (131). It is possible that treatment with immune activators such as IFN $\gamma$ and GM-CSF may be best aimed at those patients with documented "immunoparalysis" rather than at all comers with sepsis and MOF- a strategy also unsuccessful in the anti-endotoxin, anti-TNF $\alpha$, and anti-IL-1Ra trials. Our current inability to diagnose dynamic immune alterations makes treatment and understanding of the immunologic aspects of severe septic shock extremely difficult. For instance, if sepsis develops after surgery or trauma due to poor host defenses is the nature of the inflammatory response the same as that seen in sepsis evolving in a healthy host (i.e. meningococcemia)? Can septic shock evolve in a healthy host or does the development of septic shock indicate at least a transient immune deficit? Immune function is clearly altered by systemic stressors including sepsis, trauma, surgery, and burn injury. What other influences dynamically alter host defenses? What is the net effect of several such influences? Until we develop real-time immune functional assessment and fully understand where each patient lies on the spectrum of immune responsiveness, successful treatment of persistent MOF-induced by inflammatory conditions such as severe trauma and septic shock may remain elusive.

\section{CONCURRENT INFECTION}

\section{Viral Infection-Related Immunostimulation}

There is a significant body of literature demonstrating the association between viral infections (even subclinical) and potentiation or worsening of outcome from subsequent inflammatory challenges. For instance, influenza viral infection is well known to predispose humans to severe morbidity and mortality from common respiratory bacterial pathogens. Varicella also predisposes for severe streptococcal and staphylococcal toxic shock/necrotizing fasciitis syndromes. The mechanism for this is not well understood however it has been explained by the breakdown in mucosal/epithelial barriers by viral infection allowing for bacterial penetration. Animal data show that the host anti-viral immune response can potentiate lethality and the inflammatory response to endotoxin challenge during coxsackie, influenza, lymphocytic choriomeningitis virus (LCMV), and murine cytomegalovirus infection $(132,133)$. During well studied viral 
infections in mice such as LCMV, (a cause of aseptic meningitis in humans), exaggerated lethality from LPS can be seen when LPS is administered during either the innate or the adaptive anti-viral immune response. These data demonstrate priming for the response to LPS for at least a week after initiation of viral infection $(132,133)$. The mechanism for this varies depending on the nature of the ongoing anti-viral response. In the LCMV model, the innate response is characterized by high circulating interferon alpha and beta (IFN $\alpha / \beta$ ) levels which are required for the heightened sensitivity to endotoxin. Injecting IFN $\alpha$ or inducers of IFN $\alpha$ can mimic this heightened sensitivity (132). Conversely, it can be abolished in mice genetically deficient in IFN $\alpha / \beta$-responsive signaling elements. The cells responsible for this "primed state" are of monocyte/neutrophil lineage since it persists in the absence of NK, T, and B cells (132). Later, in the adaptive phase of the anti-viral response to LCMV, proliferation of cytotoxic $\mathrm{T}$ cells occurs (133). Heightened sensitivity to endotoxin administered during this time requires different cells and mediators including IFN $\gamma$ and IL-12, T and NK cells, differing from the innate response (133). Synergy between IFN $\gamma$ and endotoxin has long been appreciated, however, this work has demonstrated that activation of either IFN $\alpha / \beta$ or IFN $\gamma$ (or its inducer IL-12) can heighten the inflammatory response elicited by endotoxin. More recent work also demonstrates that pretreatment with either type of IFN can exaggerate the inflammatory response to polymicrobial septic shock induced by the cecal ligation and puncture model (134). This data suggests that when the host anti-viral response is activated, induction of IFNs $(\alpha / \beta$ or $\gamma$ ), necessary for viral containment occurs, resulting in transient hyper-reactivity of the inflammatory response to subsequent challenge (132-134). Recent molecular work has demonstrated that pretreatment with IFN $\gamma$ can upregulate the expression of MyD88 and increase IRAK kinase activity, two important intracellular components of the LPS signaling pathway through TLR4 (135). Modulation of these proteins has been suggested as a mechanism for synergy between IFN $\gamma$ and LPS and may be responsible for priming seen during viral infection also. The intracellular pathways for IFN $\alpha / \beta$ modulation of the inflammatory cascade is not well understood. These data suggest that the immune response to viral infections may dynamically modulate immune responsiveness leading to excess morbidity from secondary inflammatory challenges such as bacterial infection. 


\section{Viral Infection-Related Immunosuppression}

Some viral infections can have an opposite effect on host immune function. For instance measles virus induces a profound generalized suppression of cell-mediated immunity to include transient but significant lymphopenia, long lasting suppression of lymphoproliferative responses, decreased NK cell and neutrophil activity, and a prolonged suppression of monocyte IL-12 production and a $\mathrm{T}_{\mathrm{H}} 2 \mathrm{CD} 4$ response shift (136-139). Much of the morbidity and mortality from measles is due to secondary infection as a consequence of this altered immune state. Other viruses known to be capable of depressing host immune function include Hepatitis $\mathrm{C}$ and $\mathrm{B}$ virus (HCV, HBV), Epstein Barr Virus (EBV), Cytomegalovirus (CMV), and Pox viruses (140-145). For instance, HCV core protein interacts with the C1q complement receptor inhibiting CTL function and T cell production of IFN $\gamma$ and IL-2 contributing to prolonged viremia and increased mortality (142). Recently, immune modulation due to $\mathrm{HCV}$ has been linked to development of splenic lymphomas (143). Dendritic cells from patients with HBV infection have defective function and immature phenotype (145). The EBV immediate-early protein BZLF1 inhibits IFN $\gamma$ receptor expression and signaling (140). Pox viruses such as Vaccinia virus encode for a phosphatase which deactivates IFN $\gamma$-mediated STAT1 activation thereby interrupting IFN $\gamma$ signaling (144). Other viruses encode for soluble IFN $\alpha$ or $\gamma$ receptors and TNF $\alpha$ receptors (146). The benefit for the virus often is the creation of a host environment allowing for viral persistence. The consequence to the host is a depression in its IFN and TNF $\alpha$ signaling leaving the host with a deficient innate and adaptive immune response. More work is necessary in humans to demonstrate the contribution of underlying viral infection to morbidity and mortality from major inflammatory or infectious challenges such as major trauma or septic shock. In children who have frequent viral infections, this may be an extremely important dynamic influence on the immune system.

\section{Parasite Infection}

There is a vast amount of data demonstrating immune modulation during parasitic infections of many types. Many parasite-specific strategies have evolved to evade eradication. In doing so, many such strategies result in modulation of the global immune response. The mechanisms employed vary vastly and result in immune aberrations including the induction of 
anergy, systemic production of IL-10, nitric oxide production by host and or pathogen, $T$ cell hypo-responsiveness, or a shift to $T_{H} 2$ rather than $T_{H} 1$ response (147-151). The observation of fewer atopic and autoimmune diseases in areas of the world where endemic parasitic infections occur has led to the belief that endemic parasites may actually change the immune function of large populations thereby affecting epidemiology and geography of certain diseases (152). The impact of pre-existing immune alteration by parasites on morbidity and mortality in critical illness/injury has not been studied.

\section{Other Bacterial Stimulation}

Concurrent or sequential infection with multiple bacteria may also affect regulation of the inflammatory response. Endotoxin desensitization or tolerance with repeated administration has long been appreciated and recently been attributed to downregulation of the TLR4 pathogen recognition receptor through which LPS signals (153-156). This phenomenon can be induced in human cells as well as in animal models and may play a significant role in "immunoparalysis" (153). Conversely, numerous reports have described priming of LPS induced TNF $\alpha$ response by pretreatment with muramyl dipeptide (MDP), a bacterial cell wall component of gram positive organisms $(157,158)$. LPS signals through TLR4 and MDP signals through TLR2. The impact of signaling through one pathogen recognition receptor on signaling through others is only now beginning to be assessed. Recently, in an MDP priming model using human PBMCs, IFN $\gamma$ was identified as the "priming" mediator (157). In addition, another report has described blockade of priming by both MDP and peptidoglycan for the response to LPS with anti-CD14 antibodies (159). CD14 expression was enhanced on circulating leukocytes after treatment with these priming agents suggesting that cross talk between signaling pathways can affect the magnitude of the inflammatory response to sequential challenges. This may be extremely important in the pathogenesis of polymicrobial infections, nosocomial infections, as well as the 2-hit hypotheses of MOF development.

\section{NUTRITION}

Nutritional deficiencies both at the macronutrient and micronutrient level can cause alteration in immune function leading to enhanced susceptibility 
to infection by all forms of pathogens. Protein-energy malnutrition (PEM) is a major cause of immunodeficiency worldwide (160). PEM affects many aspects of the immune system simultaneously including depression of both innate and adaptive immune elements and have been recently reviewed (160-162). Innate response alterations include poor maintenance of mucosal barriers with defective mucus production leading to increased binding and colonization of bacteria. Fewer neutrophils are attracted to sites of infection/inflammation, lyzosomal content is diminished, and their mobilization from bone marrow is significantly delayed. NK cells exhibit poor lytic activity. Complement formation is also decreased (160-162). Adaptive response deficiencies described in PEM include impaired antibody formation including mucosal IgA production and epithelial transport, decreased $\mathrm{T}$ cell function as indicated by anergy and poor interferon production (160-162). Other defects in the immune response include reduced release of IL-1, TNF $\alpha$, and IL- 6 by ex vivo LPS-stimulated monocytes from children with PEM, which may explain attenuation of the acute phase protein responses and poor bone marrow mobilization of neutrophils (163). A characteristic feature of PEM is high concentrations of glucocorticoids which may account for downregulation of the above cytokines as well as observed downregulation of splenic IL-2 and IFN $\gamma$ mRNA in response to mitogen stimulation in animal models of PEM (160, 1634. Immune deviation from PEM is vast and when present must be considered as an extreme risk factor for infection as well as complications from poor wound healing. The threshold for immune alteration in malnutrition is not well established however, recently data demonstrates transient neutrophil dysfunction (chemotaxis and superoxide production) and depression of CD4 $\mathrm{T}$ cell counts from as little as 36 hours of fasting which correct with refeeding (165).

Micronutrient deficiency states have also been linked to secondary immunodeficiencies. Vitamins $\mathrm{A}, \mathrm{C}$, and $\mathrm{E}$ selenium, zinc, iron, polyunsaturated fatty acids, arginine, and glutamine have all been implicated in immune alterations. In addition, some reports indicate that significant micronutrient deficiency can be induced by infections in individuals already marginally deficient $(160,161,166)$. The immune impact of micronutrient deficiency states is vast as seen in PEM and has been extensively reviewed recently $(160,161)$. Aspects of the immune system impacted by micronutrients include $\mathrm{T}$ cell function with compromised DTH response, poor $\mathrm{T}$ cell proliferation, decreased IFN $\gamma$ production with a shift from $T_{H} 1$ to $T_{H} 2$ type responses $(160,161,166)$. Neutrophil and macrophage dysfunction occurs with decreased phagocytic function and altered oxygen free radical 
production. B cell dysfunction with poor antibody production and altered epithelial barrier function also has been described in association with several micronutrient deficiency states $(160,161,166)$.

Leptin, an adipocyte-derived hormone has recently been described as a key link between nutritional status and immune function. This association has been drawn because of neuroendocrine parallels (decreased T3, gonadal hormones, and increased cortisol) between leptin deficiency and starvation which is also characterized as a hypoleptinemic state $(163,167)$. Leptindeficiency, like starvation is associated with increased risk for mortality from infection, in mice and humans $(163,167)$. Experimentally, leptin exerts growth and survival effects on $\mathrm{T}$ cells thereby supporting $\mathrm{T}$ cell homeostasis $(163,167)$. Leptin and leptin receptor deficient mice have lymphoid atrophy, decreased bone marrow precursors, impaired IFN $\gamma$ production as well as phagocytic function (168). Starved mice (decreased leptin levels) also exhibit lymphoid atrophy, decreased $\mathrm{T}_{\mathrm{H}} 1$ and DTH responses which are reversible by leptin replacement $(169,170)$. Malnourished children have low leptin levels and suppressed lymphoproliferative and pro-inflammatory cytokine responses which normalize after $10 \%$ recovery of weight in parallel with normalization of leptin levels $(163,167)$. In addition acute starvation (fasting) reduces leptin levels prior to the loss of body fat (171). Obesity associated with central and peripheral leptin resistance (hyperleptinemic) as well as leptindeficiency in children is associated with increased frequency of infection $(163,167,172)$.

Some reports suggest a role for leptin in predisposition for autoimmune disease characterized by a $T_{H} 1$ excess (172). The incidence of autoimmune disease, like serum leptin levels, is higher in females compared to males (172). Experimentally, male mice treated with exogenous leptin can be rendered susceptible to autoimmune disease concomitant with $T_{H} 2$ to $T_{H} 1$ response switching (173). Due to these observations, Matarese et al suggest that leptin may be a critical determinant of immune responsiveness and that baseline immune function may be very different between obese, lean, and malnourished patients prior to any other insult. Pre-critical illness serum leptin may prove to be a significant source of inter-patient immune diversity previously ignored in the study of immune responsiveness. Further, leptin levels and responsiveness to exogenous leptin may be a useful immune monitoring tool in the future (172). 


\section{MEDICATIONS}

Many medications commonly used in ICU settings other than those described in previous sections ( $\beta$ agonists, anesthetics, and narcotics) have transient immunomodulatory effects. These include phospodiesterase inhibitors, dopamine, metoclopromide, heparin, calcium channel blockers, antihistamines, antimicrobials, prostaglandin inhibitors, and some neuroleptics. This subject has been recently reviewed thoroughly by ALKharfy et al (174) to include not only types of medications but also their site of interaction with the inflammatory response. Numerous reports describe these "unintended" effects individually, however, in the context of critical illness their impact remains poorly understood and may further add to patient diversity in studies focusing on inflammatory responsiveness. Certainly consideration of these side effects should be factored into the treatment plan for patients with severe immune perturbations.

\section{SUMMARY}

This chapter highlights several influences capable of modulating immune function in the setting of critical illness.

\begin{tabular}{|c|c|}
\hline Immunosuppressive & Immunostimulatory \\
\hline $\begin{array}{l}\text { - Stress } \\
\cdot \text { Acute or Chronic } \\
\text { - TraumaHtomorrhage } \\
\text { - Surgery } \\
\text { - Anesthetics } \\
\text { - Blood Transfusion } \\
\text { - Brain Injury } \\
\text { - Septic Shock } \\
\text { - Concurrent Infection } \\
\text { - Some viruses, parasites } \\
\text { - Poor Nutrition } \\
\text { - Medications }\end{array}$ & $\begin{array}{l}\text { - Concurrent Infection } \\
\text { : Viral Infoctions } \\
\text { - Interforon Induction } \\
\text { - Leptin }\end{array}$ \\
\hline
\end{tabular}

Table 1: Immunomodulatory influences in critical illness/injury

Several issues have been raised which suggest sources for pre-critical illness diversity in immune function beyond the usual culprits including glucocorticoids and calcineurin inhibitors (cyclosporin, tacrolimus) and genetics. These influences include coincidental infections (viral, parasitic, and other bacterial), malnutrition, and severe and chronic stress. During the critical illness setting, influences such as acute systemic stress (pain, 
hypotension), trauma/surgery with tissue injury, anesthetic choices, brain injury, infection, and medications all have the potential to modulate immune function contributing to morbidity and mortality. Many studies have focused on one concept without demonstrating how it contributes to the net immune posture of a patient during critical illness. Studies having controlled for complicated comorbidity, have continued to demonstrate immune modulation above and beyond the multitude of influences affecting controls $(85,105,117)$. This suggests that immune responsiveness exists on a dynamic continuum and that the level of response is determined by the summation of all influences including both immunostimulating as well as

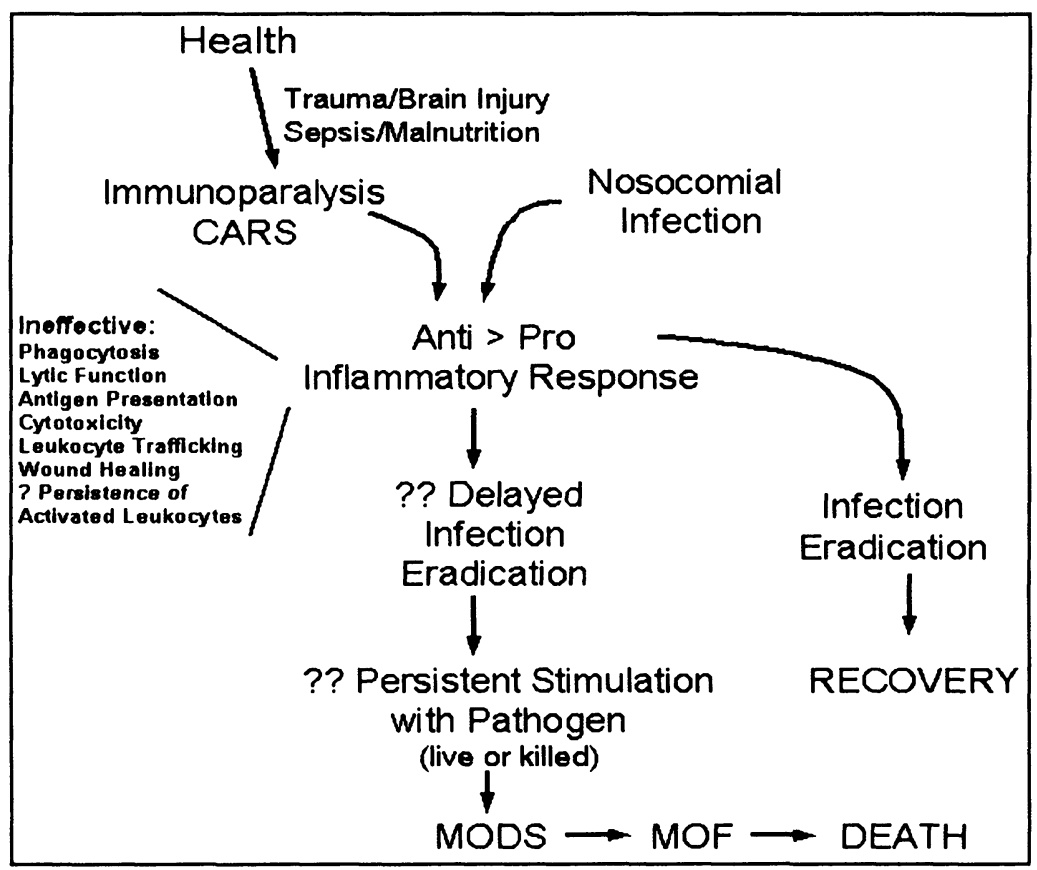

Figure 4: Many clinical states as well as therapies used in critical illness lead to immunoparalysis/CARS. Based on many studies, it is in this state that MODS and MOF can occur and worsen leading to protracted morbidity and mortality. The nature of immune-mediated tissue injury occurring in the immunoparalyzed state must be defined in order for successful therapy to be achieved. Is there delayed eradication of nosocomial infection? Is there delayed pathogen (live or dead) clearance leading to protracted stimulation? What does the adaptive immune response look like when pathogen eradication by the innate immune response has been compromised? The answer to these questions may be necessary for improved survival from illnesses resulting in a persistently downregulated inflammatory response. 
immunosuppressive influences. Considering a critically ill patient who may have been influenced by many of the factors described here, it is not surprising that as a community we have not succeeded at improving outcome from septic shock/multiple organ failure by across-the-board immunosuppression or immunostimulation. Clearly, a very complicated network is responsible for regulating the inflammatory response and

although we understand many aspects of this regulation, we have not yet assimilated all of these issues into treatment, prophylaxis, and optimal supportive care for the critically ill.

Although historically excessive pro-inflammation has been viewed as the only path to tissue injury, more recent assessment of ongoing critical illness/injury is that patients who fail to improve may be substantially immunoparalyzed $(1,7,127)$. Given these observations, perhaps future efforts should be aimed at pathways for tissue injury induced by poorly eradicated pathogens (live or dead) continuing to stimulate the inflammatory response in the setting of immunoparalysis of CARS. Data is accumulating to suggest that recovery of immune function is necessary for recovery from MOF $(1,7,127)$. For these reasons the need for continuous assessment of immune function has never been clearer. As we would consider frequent assessment of renal, pulmonary, and cardiac function essential to the management of the critically ill, so may be dynamic and periodic assessment of immune function. Strategies are being developed to provide clinically useful techniques for accurate and rapid assessment of immune function to attempt to orchestrate eradication of infection while minimizing tissue/organ injury and promoting wound healing $(2,44,66)$. Hopefully, these efforts will lead to more effective and selective treatment for dynamic immune perturbations affecting outcome in critical illness.

\section{REFERENCES}

1. Kox W, Volk T, Kox S, and Volk H. Immunomodulatory therapies in sepsis. Intensive Care Med. 2000. 26:S124-S128.

2. Volk H, Reinke P, and DockeWD. Immunologic monitoring of the inflammatory process: Which variable? When to assess? Eur J Surg. 1999. 584:70-72.

3. Kohm A and SandersV. Norepinephrine: A messenger from the brain to the immune system. Immunol Today. 2000. 21(11):539-542.

4. Chikanza IC and Grossman AB. Neuroendocrine mechanisms in rheumatic diseases. Rheum Dis Clin North Am. 2000. 26(4):693-711. 
5. Torpy D and Chrousos GP. Stress and critical illness: The integrated immune/hypothalamic-pituitary-adrenal axis response. J Intensive Care Med. 1997. 12:225-238.

6. Chrousos GP. The hypothalamic-pituitary-adrenal axis and immune-mediated inflammation. N Engl J Med. 1995. 332(20):1351-1362.

7. Chrousos GP. Therapeutic and clinical implications of systemic allergic inflammation. J Allergy Clin Immunol. 2000. 106(5):S275-S279.

8. Elenkov IJ and Chrousos G. Stress hormones, Th1/Th2 patterns, pro-antiinflammatory cytokines and susceptibility to disease. Trends Endocrinol Metab. 1999. 10:359-368.

9. Webster E, Torpy D, Elenkov IJ, and Chrousos GP. Corticotropin-releasing hormone and inflammation. Ann NY Acad Sci. 1998. 840:21-32.

10. Webster E, Elenkov IJ, and Chrousos GP. The role of corticotropin-releasing hormone in neuroendocrine-immune interactions. Mol Psychiatry. 1997. 2(5):368372.

11. Radulovic M, Dautzenberg FM, Sydow S, Radulovic J, and Spiess J. Corticotropin-releasing factor receptor 1 in mouse spleen: Expression after immune stimulation and identification of receptor-bearing cells. J Immunol. 1999. 162:3013-3021.

12. Blalock JE. Proopiomelanocortin and the immune-neuroendocrine connection. Ann NY Acad Sci. 1999. 885:161-172.

13. Marriott I and Bost KL. Il-4 and IFN- $\gamma$ up-regulate substance $P$ receptor expression in murine peritoneal macrophages. J Immunol. 2000. 165:182-191.

14. Lotz M, Vaughan J, and Carson DA. Effect of neuropeptides on production of inflammatory cytokines by human monocytes. Science. 1988. 241(4870):12181221.

15. Panerai,A,Sacerdote,P. Beta-endorphin in the immune system: a role at last? Immunol Today. 1997. 18(7):317-319.

16. Holzer P. Neurogenic vasodilatation and plasma leakage in the skin. Gen Phamacol. 1998. 30(1):5-11.

17. Serhan CN, Fierro IM, Chiang N, and Pouliot M. Cutting edge: Nociceptin stimulates neutrophil chemotaxis and recruitment: Inhibition by aspirin-triggered15-Epi-lipoxin $\mathrm{A}_{4}{ }^{1}$ J Immunol. 2001. 166:3650-3654.

18. Ben-Eliyahu S, Shakhar G, Page G, Stefanski V, and Shakhar K. Suppression of NK cell activity and of resistance to metastasis by stress: A role for adrenal catecholamines and beta-adrenoceptors. Neuroimmunomodulation. 2000. 8(3): 154-164.

19. Shakhar $G$ and Ben-Eliyahu $S$. In vivo beta-adrenergic stimulation suppresses natural killer activity and compromises resistance to tumor metastasis in rats. $\mathrm{J}$ Immunol. 1998. 160(7):3251-3258.

20. van der Poll T, Coyle SM, Barbosa K, Braxton CC, and Lowry S. Epinephrine inhibits tumor necrosis factor- $\alpha$ and potentiates interleukin 10 production during human endotoxemia. J Clin Invest. 1996. 97:713-719.

21. van der Poll T, Calvano SE, Kumar A, Coyle SM, and Lowry S. Epinephrine attenuates down-regulation of monocyte tumor necrosis factor receptors during human endotoxemia. J Leukoc Biol. 1997. 61:156-160.

22. Szabo C, Hasko G, Zingarelli B, Nemeth Z, Salzman A, Kvetan V, Pastores S, and Vizi E. Isoproterenol regulates tumour necrosis factor, interleukin-10, interleukin6 and nitric oxide production and protects against the development of vascular hyporeactivity in endotoxaemia. Immunology. 1997. 90:95-100. 
23. Siegmund B, Eigler A, Moeller J, Greten TF, Hartmann G, and Endres S. Suppression of tumor necrosis factor- $\alpha$ production by interleukin- 10 is enhanced by cAMP-elevating agents. Eur J Pharmacol. 1997. 321:231-239.

24. Agarwal SK and Marshall GD. Beta-adrenergic modulation of human type-1/type2 cytokine balance. J Allergy Clin Immunol. 2000. 105(1 Pt 1):91-98.

25. Sanders V, Baker RA, Ramer-Quinn D, Kasprowicz D, Fuchs BA, and Street N. Differential expression of the beta2-adrenergic receptor by Th1 and Th2 clones: Implications for cytokine production and B cell help. J Immunol. 1997. 158(9):4200-4210.

26. Ramer-Quinn D, Baker RA, and Sanders V. Activated T helper 1 and T helper 2 cells differentially express the beta-2-adrenergic receptor: A mechanism for selective modulation of $\mathrm{T}$ helper 1 cell cytokine production. J Immunol. 1997. 159(10):4857-4867.

27. Farmer $P$ and Pugin J. Beta-adrenergic agonists exert their "anti-inflammatory" effects in monocytic cells through the IKB/NF- $\kappa B$ pathway. Am J Physiol Lung Cell Mol Physiol. 2000. 279:L675-L682.

28. Abraham E, Kaneko DJ, and Shenkar R. Effects of endogenous and exogenous catecholamines on LPS-induced neutrophil trafficking and activation. Lung Cellular and Molecular Physiology. 1999. 276:L1-L8.

29. Spengler R, Allen RM, Remick D, Streiter R, and Kunkel S. Stimulation of $\alpha$ adrenergic receptor augments the production of macrophage-derived tumor necrosis factor. J Immunol. 1990. 145:1430-1434.]

30. Laffon M, Lu L, Modelska K, Matthay M, and Pittet J. $\alpha$-Adrenergic blockade restores normal fluid transport capacity of alveolar epithelium after hemorrhagic shock. AJP-Lung Cellular and Molecular Physiology. 1999. 277(4):L760-L768.

31. Perlstien R, Whitnall M, Abrams JS, Mougey E, and Neta R. Synergistic roles of interleukin-6, interleukin-1, and tumor necrosis factor in adrenocorticotropin response to bacterial lipopolysaccharide in vivo. Endocrinology. 1993. 132:946952.

32. Perlstein R, Mougey E, and Jackson W. Interleukin-1 and interleukin-6 act synergistically to stimulate the release of adrenocorticotropic hormone in vivo. Lymphokine Cytokine Res. 1991. 10:141-146.

33. Mastorakos G, Weber J, Magiakou M, Gunn H, and Chrousos GP. Hypothalamicpituitary-adrenal axis activation and stimulation of systemic vasopressin secretion by recombinant interleukin 6 in humans: potential implications for the syndrome of inappropriate vasopressin secretion. J Clin Endocrinol and Metab. 1994. 79:934

34. Gadient RA and Patterson PH. Leukemia inhibitory factor, interleukin 6, and other cytokines using the GP130 transducing receptor: Roles in inflammation and injury. Stem Cells. 1999. 17(3):127-137.

35. Wang Z, Ren S, and Melmed S. Hypothalamic and pituitary leukemia inhibitory factor gene expression in vivo: a novel endotoxin-inducible neuro-endocrine interface. Endocrinology. 1996. 137(7):2947-2953.

36. Chesnokova V and Melmed S. Leukemia inhibitory factor mediates the hypothalamic pituitary adrenal axis response to inflammation. Endocrinology. 2000. 141(11):4032-4040.

37. Chesnokova V, Auernhammer CJ, and Melmed S. Murine leukemia inhibitory factor gene disruption attenuates the hypothalamo-pituitary-adrenal axis stress response. Endocrinology. 1998. 139(5):2209-2216. 
38. Goehler LE, Gaykema RP, Nguyen K, Lee J, Tilders F, Maier S, and Watkins LR. Interleukin- $1 \beta$ in immune cells of the abdominal vagus nerve: a link between the immune and nervous systems? J Neurosci. 1999. 19(7):2799-2806.

39. Fleshner M, Goehler LE, Schwarts B, McGorry M, Martin D, Maier S, and Watkins LR. Thermogenic and corticosterone responses to intravenous cytokines (IL-1beta and TNF-alpha) are attenuated by subdiaphragmatic vagotomy. J Neuroimmunol. 1998. 86(2):134-141.

40. Gaykema RP, Dijkstra I, and Tilders FJ. Subdiaphragmatic vagotomy suppresses endotoxin-induced activation of hypothalamic corticotropin-releasing hormone neurons and ACTH secretion. Endocrinology. 1995. 136(10):4717-4720.

41. Hansen M, Nguyen K, Fleshner M, Goehler LE, Gaykema RP, Maier S, and Watkins LR. Effects of vagotomy on serum endotoxin, cytokines, and corticosterone after intraperitoneal lipopolysaccharide. Am J Physiol Regul Integr Compar Physiol. 2000. 278:R331-R336.

42. Gaykema RP, Goehler LE, Tilders F, Bol JG, McGorry M, Fleshner M, Maier S, and Watkins L. Bacterial endotoxin induces Fos immunoreactivity in primary afferent neurons of the vagus nerve. Neuroimmunomodulation. 1998. 5:234-240.

43. Napolitano L, Faist E, Wichmann M, and Coimbra R. Immune dysfunction in trauma. Surg Clin North Am. 1999. 79(6):1385-1416.

44. Faist E, Schinkel C, and Zimmer S. Update on the mechanisms of immune suppression of injury and immune modulation. World J Surg. 1996. 20:454-459.

45. Neidhardt R, Keel M, Steckholzer U, Safret A, Ungethuem U, Trentz O, and Ertel W. Relationship of interleukin-10 plasma levels to severity of injury and clinical outcome in injured patients. J Trauma. 1997. 42(5):863-871.

46. Hershman M, Cheadle WG, Wellhausen S, Davidson PF, and Polk H. Monocyte HLA-DR antigen expression characterizes clinical outcome in the trauma patient. Br J Surg. 1990. 77:204-207.

47. Sayeed $M$. Alterations in cell signaling and related effector functions in $T$ lymphocytes in burn/trauma/septic injuries. Shock. 1996. 5(3):157-166.

48. Markewitz A, Faist E, Lang S, Hultner L, Weinhold C, and Reichart B. An imbalance in $\mathrm{T}$-helper cell subsets alters immune response after cardiac surgery. Eur J Cardiothorac Surg. 1996. 10(1):61-67.

49. Markewitz A, Faist E, Weinhold C, Lang S, Endres S, Hultner L, and Reichart B. Alterations of cell-mediated immune response following cardiac surgery. Eur $\mathrm{J}$ Cardiothorac Surg. 1993. 7(4):193-199.

50. Wakefield C, Carey PD, Foulds S, Monson J,Guillou P. Changes in major histocompatibility complex class II expression in monocytes and $\mathrm{T}$ cells of patients developing infection after surgery. Br J Surg. 1993. 80(2):205-209.

51. Harris B and Gelfand J. The immune response to trauma. Semin Pediatr Surg. 1995. 4:77-82.

52. Svoboda P, Kantorova I, and Ochmann J. Dynamics of interleukin 1, 2, and 6 and tumor necrosis factor alpha in multiple trauma patients. J Trauma. 1994. 36:336340.

53. Livingston D, Appel SH, Wellhausen S, Sonnenfeld G, and Polk HC. Depressed interferon gamma production and monocyte HLA-DR expression after severe injury. Arch Surg. 1988. 123(11):1309-1312.

54. Christou NV, Meakins J, Gordon J, Yee J, Hassan-Zahraee M, Nohr C, Shizgal H, and MacLean L. The delayed hypersensitivity response and host resistance in surgical patients. 20 years later. Ann Surg. 1995. 222(4):534-546. 
55. De AK, Kodys K, Pellegrini J, Yeh B, Furse RK, Bankey P, and Miller-Graziano C. Induction of global anergy rather than inhibitory Th2 lymphokines mediates posttrauma $T$ cell immunodepression. Clin Immunol. 2000. 96(1):52-66.

56. Puyana J, Pellegrini J, De AK, Kodys K, Silva W, and Miller C. Both T-helper-1and $\mathrm{T}$-helper-2-type lymphokines are depressed in posttrauma anergy. $\mathrm{J}$ Trauma. 1998. 44(6):1037-1045.

57. Hensler T, Hecker H, Heeg K, Heidecke C-D, Bartels H, Barthlen W, Wagner H, Siewert J-R, and Holzmann B. Distinct mechanisms of immunosuppression as a consequence of major surgery. Infect Immun. 1997. 65(6):2283-2291.

58. Cheadle WG, Hershman M, Wellhausen S, and Polk H. HLA-DR antigen expression on peripheral blood monocytes correlates with surgical infection. Am J Surg. 1991. 161:639-645.

59. Ayala A, Ertel W, and Chaudry IH. Trauma-induced suppression of antigen presentation and expression of major histocompatibility class II antigen complex in leukocytes. Shock. 1996. 5(2):79-90.

60. Wichmann M, Ayala A, and Chaudry IH. Severe depression of host immune functions following closed-bone fracture, soft-tissue trauma, and hemorrhagic shock. Crit Care Med. 1998. 26:1372-1378.

61. Epstein J, and Brewlow MJ. Perspectives in pain management. Crit Care Med. 1999. 15(1):17-33.

62. Ayala A, Song G, Chung CS, Redmond K, and Chaudry I. Immune depression in polymicrobial sepsis: The role of necrotic (injured) tissue and endotoxin. Crit Care Med. 2000. 28: 2949-2955.

63. Bone RC. Sir Isaac Newton, sepsis, SIRS, and CARS. Crit Care Med. 1996. 24(7):1125-1128.

64. Bone RC. Immunologic Dissonance: A continuing evaluation in our understanding of the systemic inflammatory response syndrome (SIRS) and the multiple organ failure syndrome (MODS). Ann Intern Med. 1996. 125:680-687.

65. Docke WD, Randow F, Syrbe U, Krausch D, Asadullah K, Reinke P, Volk H, and Kox W. Monocyte deactivation in septic patients: restoration by IFN- $\gamma$ treatment. Nat Med. 1997. 3(6):678-681.

66. Payen D, Faivre V, Lukaszewicz A, and Losser MR. Assessment of immunological status in the critically ill. Minerva Anesthesiol. 2000. 66:351-357.

67. Kawasaki T, Ogata M, Kawasaki C, Tomihisa T, Okamoto K, and Shigematsu A. Surgical stress induces endotoxin hyporesponsiveness and an early decrease of monocyte mCD14 and HLA-DR expression during surgery. Anesth Analg. 2001. 92(5): 1322-1326.

68. Ogata M, Okamoto K, Kohriyama K, Kawasaki T, Itoh H, and Shigematsu ,A. Role of interleukin-10 on hyporesponsiveness of endotoxin during surgery. Crit Care Med. 2000. 28(9):3166-3170.

69. Nguyen N, Luketich J, Schatz S, Tran Q, Ho H, and Schauer P. Effect of open and laparoscopic surgery on cellular immunity in a swine model. Surg Laparosc Endosc Percutan Tech. 1999. 9(3):176-180.

70. LeBlanc-Louvry I, Coquerel A, Koning E, Maillot C, and Ducrotte P. Operative stress response is reduced after laparoscopic compared to open cholecystectomy: the relationship with postoperative pain and ileus. Dig Dis Sci. 2000. 45(9):17031713.

71. Karayiannakis AJ, Makri G, Mantzioka ,A, Karousos D, and Karatzas G. Systemic stress response after laparoscopic or open cholecystectomy: a randomized trial. $\mathrm{Br}$ J Surg. 1997. 84(4):467-471. 
72. Schietroma M, Carlei F, Lezoche E, Agnifili A, Enang GN, Mattucci S, Minervini $\mathrm{S}$, and Lygidakis $\mathrm{N}$. Evaluation of immune response in patients after open or laparoscopic cholecystectomy. Hepatogastroenterology. 2001. 48(39):642-646.

73. Welborn M, Oldenburg H, Hess P, Huber T, Martin T, Rauwerda J, Wesdorp R, Espat JN, Copeland EM, Moldawer L, and Seeger,J. The relationship between visceral ischemia, proinflammatory cytokines, and organ injury in patients undergoing thoracoabdominal aortic aneurysm repair. Crit Care Med. 2000. 28(9):3191-3197.

74. Holzheimer R, Gross J, and Schein M. Pro- and anti-inflammatory cytokineresponse in abdominal aortic aneurysm repair: a clinical model of ischemiareperfusion. Shock. 1999. 11(5):305-310.

75. Oldenburg H, Burress Welborn M, Pruitt J, Boelens PG, Seeger J, Martin T, Wesdorp $R$, Rauwerda $J$, van Leeuwen $P$, and Moldawer $L$. Interleukin-10 appearance following thoraco-abdominal and abdominal aortic aneurysm repair is associated with the duration of visceral ischaemia. Eur $\mathbf{J}$ Vasc Endovasc Surg. 2000. 20(2):169-172.

76. Ziegenfuss T, Wanner G, Grass C, Bauer I, Schuder G, Kleinschmidt S, Menger $M$, and Bauer M. Mixed agonistic-antagonistic cytokine response in whole blood from patients undergoing abdominal aortic aneurysm repair. Intensive Care Med. 1999. 25(3):279-287.

77. Foulds S, Mireskandari M, Kalu P, Jackson W, Cheshire NJ, Mansfield A, and Schachter M. Visceral ischemia and neutrophil activation in sepsis and organ dysfunction. J Surg Res. 1998. 75(2):170-176.

78. McBride W, Armstrong MA, Crockard AD, McMurray T, and Rea J. Cytokine balance and immunosuppressive changes at cardiac surgery: contrasting response between patients and isolated CPB circuits. Br J Anaesth. 1995. 75(6):724-733.

79. Yamaguchi T, Murakami A, Fukahara K, Ueda T, Ichida F, Miyawaki T, and Misaki $\mathrm{T}$. Changes in T-cell receptor subsets after cardiac surgery in children. Surg Today. 2000. 30(10):875-878.

80. Flohe S, Borgermann J, Dominguez RE, Majetschak M, Lim L, Kreuzfelder E, Obertacke U, Nast-Kolb D, and Schade F. Influence of granulocyte-macrophage colony-stimulating factor (GM-CSF) on whole blood endotoxin responsiveness following trauma, cardiopulmonary bypass, and severe sepsis. Shock. 1999. 12(1):17-24.

81. Ramanathan J, Coleman P, and Sibai B. Anesthetic modification of hemodynamic and neuroendocrine stress responses to cesarean delivery in women with severe preeclampsia. Anesth Analg. 1991. 73(6):772-779.

82. Tsuji H, Asoh T, Takeuchi Y, and Shirasaka C. Attenuation of adrenocortical response to upper abdominal surgery with epidural blockade. Br J Surg. 1983. 70(2): 122-124.

83. Rosenfeld B, Beattie C, Christopherson R, Norris E, Frank S, Brewlow MJ, Rock P, Parker S, Gottlieb SO, Perler B,et al. The effects of different anesthetic regimens on fibrinolysis and the development of postoperative arterial thrombosis. Perioperative Ischemia Randomized Anesthesia Trial Study Group. Anesthesiology. 1993. 79(3):435-443.

84. Perler B, Christopherson R, Rosenfeld B, Norris E, Frank S, Beattie C, and Williams, G. The influence of anesthetic method on infra-inguinal bypass graft patency: a closer look. Am Surg. 1995. 61(9):784-789. 
85. Norman $\mathrm{J}$ and Fink GW. The effects of epidural anesthesia on the neuroendocrine response to major surgical stress: a randomized prospective trial. Am Surg. 1997. 63(1):75-80.

86. Naito Y, Tamai S, Shingu K, Shindo K, Matsui T, Segawa H, Nakai Y, and Mori $\mathrm{K}$. Responses of plasma adrenocorticotropic hormone, cortisol, and cytokines during and after upper abdominal surgery. Anesthesiology. 1992. 77(3):426-431.

87. Panerai A, Manfredi B, Granucci F, and Sacerdote P. The beta-endorphin inhibition of mitogen-induced splenocytes proliferation is mediated by central and peripheral paracrine/autocrine effects of the opioid. J Neuroimmunol. 1995. 58(1):71-76.

88. Wetzel M, Steele A, Eisenstein TK, Adler MW, Henderson E, and Rogers T. Muopioid induction of monocyte chemoattractant protein-1, RANTES, and IFNgamma-inducible protein-10 expression in human peripheral blood mononuclear cells. J Immunol. 2000. 165(11):6519-6524.

89. Welters I, Menzebach A, Goumon Y, Langefeld T, Teschemacher H, Hemplemann G, and Stefano GB. Morphine suppresses complement receptor expression, phagocytosis, and respiratory burst in neutrophils by a nitric oxide and mu(3) opiate receptor-dependent mechanism. J Neuroimmunol. 2000. 111:139-145.

90. Sacerdote P, Manfredi B, Gaspani L, and Panerai A. The opioid antagonist naloxone induces a shift from Type 2 to Type 1 cytokine pattern in BALB/cJ mice. Blood. 2000. 95(6):2031-2036.

91. Welters I, Menzebach A, Goumon Y, Cadet P, Menges T, Hughes T, Hemplemann G, and Stefano GB. Morphine inhibits NF-kappa B nuclear binding in human neutrophils and monocytes by a nitric oxide-dependent mechanism. Anesthesiology. 2000. 92:1677-1684.

92. Sacerdote P, Manfredi B, Mantegazza P, and Panerai A. Antinociceptive and immunosuppressive effects of opiate drugs: a structure-related activity study. $\mathrm{Br} \mathbf{J}$ Pharmacol. 1997. 121(4):834-840.

93. Moeniralam HS, Endert E, Ackermans MT, van Lanschot JJB, Sauerwein HP, and Romijn JA. The opiate sufentanil alters the inflammatory, endocrine, and metabolic responses to endotoxin in dogs. Am J Physiol. 1998. 275(3):E440-E447.

94. Vamvakas E and Blajchman MA. Deleterious clinical effects of transfusionassociated immunomodulation: fact or fiction? Blood. 2001. 97(5):1180-1195.

95. Blajchman MA, Dzik S, Vamvakas E, Sweeney J, and Snyder E. Clinical and molecular basis of transfusion-induced immunomodulation: summary of the proceedings of a state-of-the-art conference. Transfusion Medicine Reviews. 2001. 15(2):108-135.

96. Ghio M, Contini P, Mazzei C, Merlo A, Filaci G, Setti M, Indiveri F, and Puppo F. In vitro immunosuppressive activity of soluble HLA class I and Fas ligand molecules: Do they play a role in autologous blood transfusion? Transfusion. 2001. 41(8):988-996.

97. Puppo F, Ghio M, Contini P, Mazzei C, and Indiveri F. Fas, Fas ligand, and transfusion immunomodulation. Transfusion. 2001. 31:416-418.

98. Chin-Yee I, Keeney M, Krueger L, Dietz G, and Moses G. Supernatant from stored red cells activates neutrophils. Transfus Med. 1998. 8(1):49-56.

99. Silvergleid A. Leukoreduction to prevent complications of blood transfusion. www.UpToDate®.com. 2002.

100. Biffl W, Moore E, Offner P, Ciesla DJ, Gonzalez RJ, and Silliman C. Plasma from aged stored red blood cells delays neutrophil apoptosis and primes for 
cytotoxicity: abrogation by poststorage washing but not prestorage leukoreduction. J Trauma. 2001. 50:426-432.

101. Quattrocchi K, Frank EH, Miller C, MacDermott J, Hein L, Frey L, and Wagner F. Suppression of cellular immune activity following severe head injury. J Neurotrauma. 1990. 7(2):77-87.

102. Asadullah K, Woiciechowsky C, Docke WD, Egerer K, Know WJ, Vogel S, Sterry W, and Volk HD. Very low monocytic HLA-DR expression indicates high risk of infection-immunomonitoring for patients after neurosurgery and patients during high dose steroid therapy. Eur J Emerg Med. 1995. 2(4):184-190.

103. Wilson N, Gooding A, Peterson B,Bastian JF. Anergy in pediatric head trauma patients. Am J Dis Child. 1991. 145(3):326-329.

104. Meert K, Long M, Kaplan J, and Sarnaik A. Alterations in immune function following head injury in children. Crit Care Med. 1995. 23(5):822-828.

105. Asadullah K, Woiciechowsky C, Docke WD, Liebenthal C, Wauer H, Kox W, Volk HD, Vogel S, and von Baehr R. Immunodepression following neurosurgical procedures. Crit Care Med. 1995. 23:1976-1983.

106. Quattrocchi KB, Frank EH, Miller C, Amin A, Issel B, and Wagner,F. Impairment of helper T-cell function and lymphokine-activated killer cytotoxicity following severe head injury. J Neurosurg. 1991. 75(5):766-773.

107. Miller C, Quattrocchi K, Frank EH, Issel B, and Wagner F. Humoral and cellular immunity following severe head injury: review and current investigations. Neurol Res. 1991. 13(2):117-124.

108. Quattrocchi K, Frank EH, Miller C, Dull ST, Howard R, and Wagner F. Severe head injury: effect upon cellular immune function. Neurol Res. 1991. 13(1):13-20.

109. Csuka E, Morganti-Kossmann M, Lenzlinger P, Joller H, Trentz O, and Kossmann T. IL-10 levels in cerebrospinal fluid and serum of patients with severe traumatic brain injury: Relationship to IL-6, TNF-alpha, TGF-betal and blood-brain barrier function. J Neuroimmunol. 1999. 101(2):211-221.

110. Whalen M, Carlos TM, Kochanek P, Wisniewski S, Bell MJ, Carcillo JA, Clark RS, DeKosky ST, and Adelson P. Soluble adhesion molecules in CSF are increased in children with severe head injury. J Neurotrauma. 1998. 15(10):777787.

111. Woiciechowsky C, Schoning B, Cobanov J, Lanksch W, Volk H, and Docke WD. Early IL-6 plasma concentrations correlate with severity of brain injury and pneumonia in brain-injured patients. J Trauma. 2002. 52(2):339-345.

112. Lenzlinger PM, Hans VH, Joller-Jemelka HI, Trentz O, Morganti-Kossmann MC, and Kossmann T. Markers for cell-mediated immune response are elevated in cerebrospinal fluid and serum after severe traumatic brain injury in humans. $J$ Neurotrauma. 2001. 18(5):479-489.

113. Robertson C, Minamino N, Ruppel R, Kangawa K, Adelson P, Tsuji T, Wisniewski S, Ohta $\mathrm{H}$, Janesko $\mathrm{K}$, and Kochanek P. Increased adrenomedullin in cerebrospinal fluid after traumatic brain injury in children: A preliminary report. Acta Neurochir Suppl. 2000. 76:419-421.

114. Stahel P, Kossmann T, Joller H, Trentz O, and Morganti-Kossmann M. Increased interleukin-12 levels in human cerebrospinal fluid following severe head trauma. Neurosci Lett. 1998. 249(203):123-126.

115. Lenzlinger PM, Marx A, Trentz O, Kossman T, and Morganti-Kossman MC. Prolonged intrathecal release of soluble Fas following severe traumatic brain injury in humans. J Neuroimmunol. 2002. 122:167-174. 
116. Woiciechowsky C, Schoning B, Lanksch W, Volk H, and Docke WD. Mechanisms of brain-mediated systemic anti-inflammatory syndrome causing immunodepression. J Mol Med. 1999. 77:769-780.

117. Woiciechowsky C, Assadullah K, Nestler D, Eberhardt B, Platzer C, Schoning B, Glockner F, Lanksch W, Volk HD, and Docke WD. Sympathetic activation triggers systemic interleukin-10 release in immunodepression induced by brain injury. Nat Med. 1998. 4:808-813.

118. Wolk K, Docke WD, von Baehr V, Volk HD, and Sabat R. Impaired antigen presentation by human monocytes during endotoxin tolerance. Blood. 2000. 96:218-223.

119. Ertel W, Kremer J, Kenney J, Steckholzer U, Jarrar D, Trentz O, and Schildberg F. Downregulation of proinflammatory cytokine release in whole blood from septic patients. Blood. 1995. 85(5):1341-1347.

120. Ayala A, Chung CS, Xu Y, Evans TA, Redmond K, and Chaudry,IH. Increased inducible apoptosis in $\mathrm{CD} 4+\mathrm{T}$ lymphocytes during polymicrobial sepsis is mediated by Fas ligand and not endotoxin. Immunology. 1999. 97(1):45-55.

121. Volk,H, Reinke,P,Docke,WD. Clinical Aspects: From systemic inflammation to "immunoparalysis". Chem Immunol. 2001. 74:162-177.

122. Hotchkiss R, Tinsley K, Swanson P, Schmieg R, Hui J, Chang KC, Osborne D, Freeman BD, Cobb JP, Buchman T, and Karl I. Sepsis-induced apoptosis causes progressive profound depletion of $\mathrm{B}$ and $\mathrm{CD} 4+\mathrm{T}$ lymphocytes in humans. $\mathrm{J}$ Immunol. 2001. 166:6963

123. Hotchkiss R, Swanson P, Freeman BD, Tinsley K, Cobb JP, Matuschak G, Buchman T, and Karl I. Apoptotic cell death in patients with sepsis, shock, and multiple organ dysfunction. Crit Care Med. 1999. 27:1230

124. Lauw F, ten Hove T, Dekkers PE, de Jonge E, van Deventer S, and van der Poll T. Reduced Th1, but not Th2, cytokine production by lymphocytes after in vivo exposure of healthy subjects to endotoxin. Infect Immun. 2000. 68(3):1014-1018.

125. Hafenrichter D, Roland C, Mangino M, and Flye MW. The Kupffer cell in endotoxin tolerance: Mechanisms of protection against lethal endotoxemia. Shock. 1994. 2(4):241-256.

126. West M, Manthei R, and Burbrick MP. Autoregulation of hepatic macrophage activation in sepsis. J Trauma. 1993. 34(4):473-479.

127. Hall MW and Carcillo JA. Immune paralysis and the state of immunologic dissonance in pediatric multiple organ dysfunction syndrome (MODS). 2001. 29:A20.

128. Schinkel C, Licht K, Zedler S, Schinkel S, Fuchs D, and Faist E. Perioperative treatment with human recombinant interferon-gamma: A randomized double-blind clinical trial. Shock. 2001. 16(5):329-333.

129. Presneill J, Harris T, Stewart A, Cade JF, and Wilson J. A randomized phase II trial of granulocyte-macrophage colony-stimulating factor therapy in severe sepsis with respiratory dysfunction. Am J Respir Crit Care Med. 2002. 166(2):129-130.

130. Bilgin K, Yaramis A, Haspolat K, Tas M, Gunbey S, and Derman O. A randomized trial of granulocyte-macrophage colony-stimulating factor in neonates with sepsis and neutropenia. Pediatrics. 2001. 107(1):36-41.

131. Kox W, Bone RC, Krausch D, Docke WD, Kox S, Wauer H, Egerer K, Querner S, Asadullah K, von Baeher R, and Volk HD. Interferon gamma-lb in the treatment of compensatory anti-inflammatory response syndrome. A new approach: proof of principle. Arch Intern Med. 1997. 157(4):389-393. 
132. Doughty L, Nguyen K, Durbin J, and Biron C. A role for IFN-alpha beta in virus infection-induced sensitization to endotoxin. J Immunol. 2001. 166:2658-2664.

133. Nguyen $\mathrm{K}$ and Biron $\mathrm{C}$. Synergism for cytokine-mediated disease during concurrent endotoxin and viral challenges: roles for NK and T cell IFN-gamma production. J Immunol. 1999. 162:5238-5246.

134. Doughty LA, Chung C, Lomas J, Nguyen K, Biron C, Ayala A. Mechanisms of Viral Potentiation of Inflammation: IFN $\alpha$ Modulation of the Cytokine Response to Sepsis. Shock. 2001;15:104.

135. Bosisio D, Polentarutti N, Sironi M, Bernasconi S, Miyake K, Webb G, Martin M, Mantovani,A, and Muzio M. Stimulation of toll-like receptor 4 expression in human mononuclear phagocytes by interferon-gamma: A molecular basis for priming and synergism with bacterial lipopolysaccharide. Blood. 2002. 99(9):3427-3431.

136. Schneider-Schaulies S, Bieback K, Avota E, Klagge I, and terMeulen V. Regulation of gene expression in lymphocytes and antigen-presenting cells by measles virus: consequences for immunmodulation. J Mol Med. 2002. 80(2):7385.

137. Schneider-Schaulies S, Niewiesk S, Schneider-Schaulies J, and terMeulen V. Measles virus induced immunosuppression: Targets and effector mechanisms. Curr Mol Med. 2001. 1(2):163-181.

138. Avota E, Avots A, Niewiesk S, Kane LP, Bommhardt U, ter Meulen V, and Schneider-Schaulies,S. Disruption of Akt kinase activation is important for immunosuppression induced by measles virus. Nat Med. 2001. 7(6):725-731.

139. Atabani SF, Byrnes AA, Jaye A, Kidd M, Magnusen AF, Whittle,H, and Karp CL. Natural measles causes prolonged suppression of interleukin-12 production. $J$ Infect Dis. 2001. 184:1-9.

140. Morrison T, Mauser A, Wong A, Ting,J, and Kenney S. Inhibition of IFN- $\gamma$ signaling by an Epstien-Barr virus immediate-early protein. Immunity. 2002. 15:787-799.

141. Moutaftsi M, Mehl A, Borysiewicz LK, and Tabi Z. Human cytomegalovirus inhibits maturation and impairs function of monocyte-derived dendritic cells. Blood. 2002. 99(8):2913-2921.

142. Yao Z, Ray S, Wisen-Vandervelde A, Waggoner,S, and Hahn Y. Hepatitis C virus: Immunosuppression by complement regulatory pathway. Viral Immunol. 2001. 14(4):277-295.

143. Large M, Kittlesen D, and Hahn Y. Suppression of host immune response by the core protein of Hepatitis $\mathrm{C}$ virus: Possible implications for Hepatitis $\mathrm{C}$ virus persistence. J Immunol. 1999. 162:931-938.

144. Najarro P, Traktman P, and Lewis,J. Vaccinia virus blocks gamma interferon signal transduction: Viral VH1 phosphatase reverses Stat 1 Activation. Journal of Virology. 2001. 75(7):3185-3196.

145. Wang F, Xing L, Liu M, Zhu C, Liu H, Wang,H, and Lei Z. Dysfunction of peripheral blood dendritic cells from patients with chronic hepatitis B virus infection. World J Gastroenterol. 2001. 7(4):537-541.

146. Guidotti,LG, and Chiu JH. To kill or to cure: Options in host defense against viral infection. Curr Opin Immunol. 1996. 8:483-

147. Zambrano-Villa S, Rosales-Borjas D, Carrero JC, and Ortiz-Ortiz L. How protozoan parasites evade the immune response. Trends Parasitol. 2002. 18(6):272-278. 
148. Bogdan $C$ and Rollinghoff $M$. The immune response to Leishmania: Mechanisms of parasite control and evasion. Int J Parasitol. 1998. 28(1):121-134.

149. Kotwal GJ. Microorganisms and their interaction with the immune system. J Leukoc Biol. 1997. 62(4):415-429.

150. Luder C, Gross U, and Lopes $M$. Intracellular protozoan parasites and apoptosis: Diverse strategies to modulate parasite-host interactions. Trends Parasitol. 2001. 17(10):480-486.

151. Wikel S and Alarcon-Chaidez FJ. Progress toward molecular characterization of ectoparasite modulation of host immunity. Veterinary Parasitology. 2001. 101:275-287.

152. Cooper PJ. Can intestinal helminth infections (geohelminths) affect the development and expression of asthma and allergic disease? Clin Exp Immunol. 2002. 128(3):398-404.

153. Wolk K, Docke WD, von Baehr V, Volk HD, and Sabat R. Comparison of monocyte functions after LPS- or IL-10-induced reorientation: Importance in clinical immunoparalysis. Pathobiology. 1999. 67:253-256.

154. Sato S, Nomura F, Kawai T, Takeuchi O, Muhlradt P, Takeda K, and Akira S. Synergy and cross-tolerance between toll-like receptor (TLR) 2- and TLR4mediated signaling pathways. J Immunol. 2000. 165(12):7096-7101.

155. Medvedev A, Kopydlowski K, and Vogel S. Inhibition of lipopolysaccharideinduced signal transduction in endotoxin-tolerized mouse macrophages: dysregulation of cytokine, chemokine, and toll-like receptor 2 and 4 gene expression. J Immunol. 2000. 164(11):5564-5574.

156. Nomura F, Akashi S, Sakao Y, Sata S, Kawai T, Matsumoto M, Nakanishi K, Kimoto M, Miyake K, Takeda K, and Akira S. Cutting edge: endotoxin tolerance in mouse peritoneal macrophages correlates with down-regulation of surface tolllike receptor 4 expression. J Immunol. 2000. 164(7):3476-3479.

157. Beigneaux A, Huang,J, Le Contel C, Heremans H, and Parant M. Differential role of interferon-gamma in the potentiating effect of muramyl peptides for enhanced responses to lipopolysaccharide in mice: effect of cyclosporin A. J Interferon Cytokine Res. 1995. 15(4):359-365.

158. Parant M, Parant F, Vinit M, Jupin C, Noso Y,Chedid L. Priming effect of muramyl peptides for induction by lipopolysaccharide of tumor necrosis factor production in mice. J Leukoc Biol. 1990. 47(2):164-169.

159. Wang J, Jorgensen P, Ellingsen EA, Almiof M, Thiemermann C, Foster SJ, Aasen $A$, and Solberg R. Peptidoglycan primes for LPS-induced release of proinflammatory cytokines in whole human blood. Shock. 2001. 16(3):178-182.

160. Field CJ, Johnson I, and Schley P. Nutrients and their role in host resistance to infection. J Leukoc Biol. 2002. 71:16-32.

161. Scrimshaw $N$ and SanGiovanni J. Synergism of nutrition, infection, and immunity: An overview. Am J of Clin Nutr. 1997. 66(2):464S-477S.

162. Woodward B. Protein, Calories, and Immune Defenses. Nutr Rev. 1998. 56(1):S84-S92.

163. Palacio A, Lopez M, Perez-Bravo F, Monkeberg F, and Schlesinger L. Leptin levels are associated with immune response in malnourished infants. J Clin Endocrinol and Metab. 2002. 3040-3046.

164. Soliman A, ELZalabany MM, Salama M, and Ansari BM. Serum leptin concentrations during severe protein-energy malnutrition: correlation with growth parameters and endocrine function. Metabolism. 2000. 49(7):819-825. 
165. Walrand S, Moreau K, Caldefied F, Tridon A, Chassagne J, Portefaix G, Cynober L, Beaufrere B, Vasson $M$, and Boirie Y. Specific and nonspecific immune responses to fasting and refeeding differ in healthy young adult and elderly persons. Am J Clin Nutr. 2001. 74(5):670-678.

166. Bhaskaram P. Micronutrient malnutrition, infection and immunity: An overview. Nutr Rev. 2002. 60(5):S40-S45.

167. Grunfeld C. Leptin and the immunosuppression of malnutrition. J Clin Endocrinol and Metab. 2002. 87(7):3038-3039

168. Ozata M, Ozdemir I, and Licinio J. Human leptin deficiency caused by a missense mutation: Multiple endocrine defects, decreased sympathetic tone, and immune system dysfunction indicate new targets for leptin action, greater central than peripheral resistance to the effects of leptin, and spontaneous correction of leptinmediated defects. J Clin Endocrinol and Metab. 1999. 84:3686-3695.

169. Ahima RS, Prabakaran D, Mantzoros C, Qu D, Lowell B, Maratos-Flier E, and Flier JS. Role of leptin in the neuroendocrine response to fasting. Nature. 1996. 382:250-252.

170. Lord G, Matarese G, Howard J, Baker R, Bloom S, and Lechler R. Leptin modulates the $\mathrm{T}$ cell immune response and reverses starvation-induced immunosuppression. Nature. 1998. 394:897-

171. Boden G, Chen X, Mozzoli M, and Ryan I. Effect of fasting on serum leptin in normal human subjects. J Clin Endocrinol and Metab. 1996. 81:3419-3423.

172. Matarese G, LaCava A, Sanna V, Lord,G, Lechler,R, Fontana S, and Zappacosta $\mathrm{S}$. Balancing susceptibility to infection and autoimmunity: A role for leptin? Trends in Immunology. 2002. 23(4):182-187.

173. Matarese G, Sanna V, Di Giacomo A, Lord GM, Howard JK, Bloom SR, Lechler RI, Fontana S, and Zappacosta S. Leptin potentiates experimental autoimmune encephalomyelitis in SJL female mice and confers susceptibility to males. Eur J Immunol. 2001. 31:1324-1332.

174. ALKharfy KM, Kellum JA, and Matzke GR. Unintended immunomodulation: Part II. Effects of pharmacological agents on cytokine activity. Shock. 2000. 13(5):346-360. 